IFC workshop on "Combining micro and macro statistical data for financial stability analysis. Experiences, opportunities and challenges"

Warsaw, Poland, 14-15 December 2015

\title{
Systemic risk, interbank market contagion, and the lender of last resort function ${ }^{1}$
}

\author{
Marcin Jerzy Michalski, Michael Bowe, Olga Kolokolova, \\ University of Manchester/Manchester Business School
}

1 This paper was prepared for the meeting. The views expressed are those of the authors and do not necessarily reflect the views of the BIS or the central banks and other institutions represented at the meeting. 


\title{
Systemic Risk, Interbank Market Contagion, and the Lender of Last Resort Function
}

\author{
Michael Bowe, Olga Kolokolova, Marcin Jerzy Michalski ${ }^{1}$
}

\begin{abstract}
We develop a theoretical model examining the financial stability policy of a central bank serving as both the lender of last resort and the regulator of the financial system. Our model accommodates the possibility of financial contagion through interbank market linkages, and adverse feedback from the financial system to the real economy. We identify the volume of activity in the interbank money market, the relative riskiness of the agents in the financial system, and the probability of systemic distress as the key factors influencing the design of financial stability policy. Furthermore, results of simulating the model indicate that there is a substitution effect between reducing the expected scope of a central bank's assistance to an institution in distress and increasing bank capital requirements.
\end{abstract}

Keywords: Financial Stability, Central Bank Policy, Lender of Last Resort, Banking Crisis, Bank Regulation, Interbank Market.

JEL classification: E58, G01, G21, G28.

${ }^{1}$ Alliance Manchester Business School, The University of Manchester. Please direct all enquiries and comments about this paper to Marcin Michalski (marcin.michalski@manchester.ac.uk) 


\section{Contents}

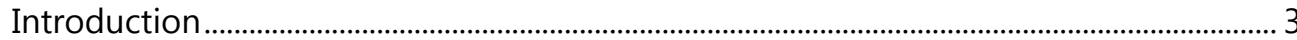

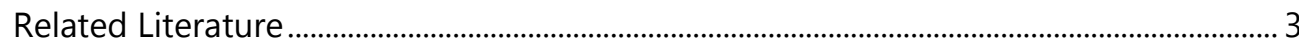

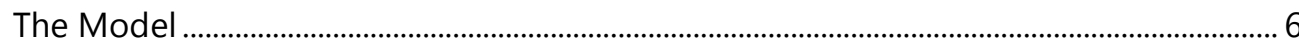

The Commercial Banks.......................................................................................................... 6

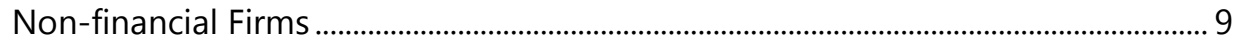

The Central Bank …………………………………………………………………….... 9

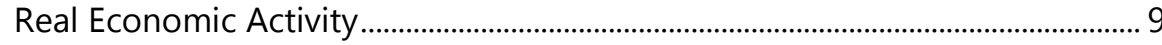

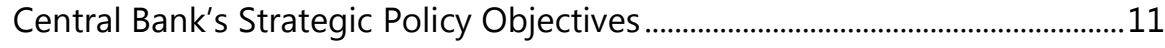

Structure and Evolution of the Game .................................................................................11

Solving the Model...........................................................................................................

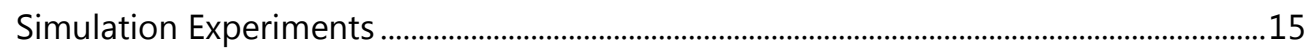

Baseline Simulation ............................................................................................................. 15

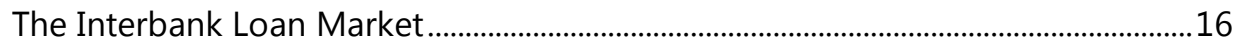

The Central Bank's Value Function........................................................................................19

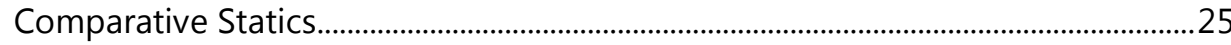

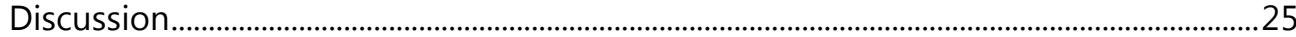

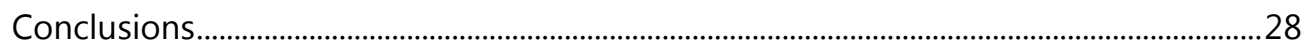

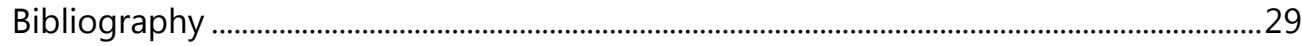

Appendix A: Derivation of the Interbank Loan Size Functions.............................................32

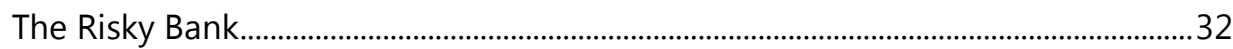

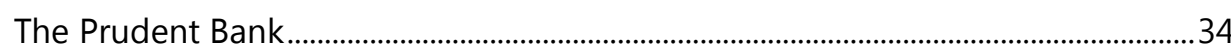




\section{Introduction}

The shortcomings of a financial stability policy based upon microprudential bank regulation and the provision of liquidity to solvent but illiquid institutions in the context of an increasingly complex and interconnected financial system were revealed by the 2007 - 2009 financial crisis. The severity of this crisis initiated a fundamental re-evaluation of the role that central banks and bank capital regulation play in promoting the resilience of the financial system. However, the question of precisely identifying the targets and objectives of a new stability framework remains the subject of an ongoing academic and policy debate.

We believe this is the first study to develop an analytical framework investigating the combined impact of bank regulatory capital requirements and a central bank's commitment to act as the lender of last resort on the operation of an economic system in which financial sector dependencies are mediated through an interbank market. We consider different regulatory policies with varying scopes of the policymaker's intervention. Specifically, the stylised economic system consists of a central bank serving as both the lender of last resort and the regulator of the financial system, two commercial banks interacting through an interbank market, and a non-financial, economic sector producing real output. Our approach involves identifying the appropriate design for central bank regulatory policy and market intervention whose objective is to maximise the difference between expected economic output in the system and a range of potential costs associated with financial distress. In this context, we offer a holistic view of financial stability.

The key factors influencing the design of the optimal central bank financial stability policy are identified to be the volume of interbank lending, the relative riskiness of financial institutions in the system, and the probability of any crisis becoming systemic. Our results also establish the existence of a substitution effect between central bank policies designed to moderate the expectations of financial institutions relating to receiving assistance, and regulations increasing bank capital requirements. Finally, the model also emphasises the importance of a central bank's commitment to fostering the stable functioning of the interbank money market in times of economic stress.

\section{Related Literature}

The various literatures analysing a central bank's lender of last resort function, financial contagion, and prudential bank regulation have been evolving largely independently until recently. Our paper contributes to this ongoing research agenda by attempting to develop a more general, unified theory connecting financial stability and regulatory policy.

The original objectives of a lender of last resort are clarified in Thornton (1802) and Bagehot (1873), and suggest that "very large loans at very high interest rates are the best remedy for the worst malady of the money market [...] Any notion that money is not to be had, or that it may not be had at any price, only raises alarm to panic, and enhances panic to madness" (Bagehot, 1873: pp. 56 - 57). This claim finds support in Diamond and Dybvig's (1983) formulation, which shows that the efficient 
functioning of the banking system requires either a formal deposit insurance scheme or a central bank's commitment to lend to solvent but illiquid institutions. Such guarantees eliminate the possibility of self-fulfilling prophecies of bank runs destabilising the system.

Providing such assistance, however, enables financial institutions to escape market discipline and promotes forbearance (Freixas and Parigi, 2014). Indeed, the empirical evidence in Dam and Koetter (2012) indicates that default probabilities in the financial system increase significantly following a policymaker's intervention. This trade-off between preventing financial contagion and creating moral hazard is formalised in Goodhart and Huang's (2005) seminal lender of last resort model. The existence of a lender of last resort also affects financial institutions' financing decisions, as they come to expect the central bank's collateral quality policy may be loosened under crisis conditions (Wagner, 2007, Ratnovski, 2009, Koulischer and Struyven, 2014).

To address this problem, Goodhart and Huang (2005) propose an intervention strategy based around the notion of constructive ambiguity, the doctrine of not precisely specifying in advance the precise goals and targets of financial stability policy and the mechanism of any central bank intervention. They demonstrate that this encourages financial institutions to behave as if they are not protected, although the central bank may actually stand ready to intervene in a crisis. Nijskens (2014) highlights the fact that the credibility of such an approach is largely determined by the central bank's reputation for strictness. The recent financial crisis, however, has put the efficacy of constructive ambiguity in doubt. Commentators argue that the lack of a clear understanding of how central banks were going to respond to the crisis led to sudden significant changes in assistance expectations, with devastating consequences for financial system stability (Vinogradov, 2012).

Consequently, our model departs from the traditional analysis of constructive ambiguity. We examine a system in which the central bank's policy is common knowledge, thereby allowing it to manage financial institutions' assistance expectations. This approach is akin to forward guidance on future interest rates, in which the central bank communicates the details of its monetary policy in order to correct faulty private expectations, thus reducing misallocation of economic resources such expectations may induce ${ }^{2}$ (Blinder, et al., 2008).

Gorton and Huang (2004) point out that while the central bank should be committed to assisting solvent but illiquid institutions, bailouts of insolvent banks provide an additional source of emergency liquidity. Moreover, during crisis periods illiquidity and insolvency often become indistinguishable. One consequence of this identification problem is that central banks may abandon the traditional principles associated with the lender of last resort function by extending loans or engaging in large-scale open-market purchases of the non-performing assets of those nondepository institutions deemed to be systemically important (Buiter, 2008, Aglietta and Mojon, 2014). Freixas and Parigi (2014) conclude that the traditional view, namely that a central bank should only assist solvent but illiquid institutions often

${ }^{2}$ This reflects the spirit of Friedman's (1962) analysis, who argues that following a well-publicised policy has favourable effects on people's attitudes and expectations, which in turn leads to better outcomes than if the same policy actions are implemented on a discretionary basis. 
leads to a simplistic analysis of financial stability, and to an artificial separation between lending of last resort and bank bail-out interventions.

Many commentators focus on the interbank money market as the most prominent channel of financial contagion in a banking system. It interconnects banks' balance sheets, and acts to rapidly propagate one agent's distress throughout the financial system (Rochet and Tirole, 1996, Allen and Gale, 2000, Freixas, et al., 2000, Kiyotaki and Moore, 2002). ${ }^{3}$ Hence, by intervention in the interbank market the lender of last resort seeks to contain a crisis before it is transmitted any further (Goodhart and Huang, 2005). Further, interbank interest rates transmit the effects of a change in the central bank's policy rate into the real economy, and are now commonly used as benchmark rates in pricing a variety of derivatives used by non-financial firms (International Monetary Fund, 2008, Brunnermeier, 2009). Thus, as a result of the consequent impact on the real sector of the economy, the costs of a sudden evaporation of confidence in this market can be substantial, and severely impede a central bank's ability to achieve its policy objectives (Nagel, 2013). Domanski, et al. (2014) argue that the growing importance of the interbank market calls for development of new operating frameworks that would allow for greater flexibility during times when banking sector liquidity is compromised. As our model explicitly accounts for the effects of financial contagion arising out of liquidity channel linkages intermediated through the interbank market, it contributes to identifying how a central bank may achieve this objective.

Existing theories of microprudential regulation are comprehensively surveyed in Dewatripont and Tirole (1994) and VanHoose (2007). This regulatory approach focuses on limiting financial distress in individual institutions by ensuring that they are well-capitalised and managed prudently (Borio, 2003). The regulatory paradigm shift towards macroprudential regulation seeks to limit the risk of system-wide financial distress resulting in a significant loss of real output (Borio, 2003). Galati and Moessner (2010) and Claessens (2014) provide an overview of macroprudential policy tools, detailing the distinctions between the two classes of regulatory regime. Repullo and Suarez (2013) argue that macroprudential regulations are less procyclical and result in an increased accumulation of capital reserves in economic expansions, thereby increasing the resilience of the financial system.

Recent regulatory changes, however, have been initiated without any solid theoretical foundations lending support to their efficacy. Examinations of their effectiveness primarily undertake qualitative assessments, or provide early estimates of the economic costs and resulting impact of the current transition towards macroprudentiality (e.g., Slovik and Cournède, 2011, or Angelini, et al., 2014). Arnold, et al. (2012) discuss the practical problems in accurately identifying systemic risk, a core concept around which the new framework is built. Giese, et al. (2013) survey the literature to identify the possible transmission channels of macroprudential policy and its effects on credit supply. They conclude that it is impossible to identify with certainty any effects it is going to have ex ante. Mészáros

\footnotetext{
${ }^{3}$ Notwithstanding the fact that Acemoglu, et al. (2015) show that shocks of sufficiently small magnitude
} are more efficiently absorbed by a more densely interconnected financial network. 
(2013) emphasises the fact that the new framework suffers from a number of internal and technical difficulties, arguing that it may require an unprecedented level of intervention in order to achieve its new objectives. The theory of systemic risk outlined by Acharya (2009) suggests that any system relying on the use of riskweighted assets is fundamentally unsuitable in a systemic context, and thus ought to be replaced by a framework based on correlations between banks' asset returns. Van den Heuvel's (2008) model shows that bank capital requirements reduce banks' ability to create liquidity in the economy, creating a welfare cost equal to a $11 \%$ permanent reduction in consumption. While our model accommodates this adverse relation between bank capital requirements, credit supply and economic output, another contribution is that its formulation enables us to examine the joint effects of central bank regulation and lending of last resort on the efficient design of financial stability policy.

Finally, we contribute to the literature investigating the appropriate institutional allocation of the roles of lender of last resort and regulator of the banking system. Goodhart and Schoenmaker (1995) find no empirical evidence in support of either combining or separating these functions. At the same time, Kahn and Santos (2005) suggest that while centralising these roles may lead to excessive forbearance, a multi-institutional arrangement may instead create substantial costs arising from coordination failures. In contrast, our results show that combining the functions of the lender of last resort and the regulator of the banking system may improve the effectiveness of financial stability policy.

\section{The Model}

The model economy consists of a central bank, two commercial banks connected through an interbank market, and firms operating in the real economy. The banks use long-term liabilities and equity capital to provide loans to non-financial firms who invest in positive net present value projects. The central bank's policy objective is to appropriately deploy its mandate as lender of last resort and banking system regulator in order to maximise the difference between real economic output generated in the system and the potential costs of economic distress. In this section we first detail the nature of the agents' behaviour in the model. We then proceed to discuss the structure of the interaction between them.

\section{The Commercial Banks}

Initially, at $t=0$ the two commercial banks are of the same size, but have different exogenously-determined risk profiles. Both banks finance their operations through long-term liabilities and equity capital, and maintain a certain level of central bank mandated capital reserves dependent upon the amount of risky assets they hold. The time to maturity of the liabilities is sufficiently distant to make them irrelevant for decision-making within the time frames considered in the model. Thus, the levels of both long-term liabilities and equity capital are assumed to be fixed.

The interbank money market is the conduit through which the banks interact to reallocate their initial endowment of risky assets. The lending bank is characterised 
as the prudent bank because it diversifies its portfolio of assets, while the second, risky bank borrows in the interbank market in order to leverage its investment position, thereby taking on more risk. Table 1 depicts the balance sheet structures of the two banks. Panel A captures their initial balance sheet position, Panels B and $C$ show the post-transaction changes.

Balance sheet structures of the two commercial banks

Panel A: Initial balance sheet structure

Table 1

\begin{tabular}{ll}
\hline \multicolumn{1}{c}{ Assets } & \multicolumn{1}{c}{ Liabilities } \\
\hline Risky Assets: $a_{t}$ & Long-term Liabilities: $l$ \\
\hline Reserves: $k_{t}$ & Equity Capital: $c$ \\
\hline
\end{tabular}

Panel B: Post-transaction balance sheet of the risky bank

\begin{tabular}{ll}
\hline \multicolumn{1}{c}{ Assets } & \multicolumn{1}{c}{ Liabilities } \\
\hline Risky Assets + Interbank Loan: $a_{t}+\frac{1}{1+\kappa} i_{t}$ & Interbank Loan: $i_{t}$ \\
\hline Reserves: $k_{u, t}$ & Long-term Liabilities: $l$ \\
\hline & Equity Capital: $c$
\end{tabular}

Panel C: Post-transaction balance sheet of the prudent bank

\begin{tabular}{ll}
\hline \multicolumn{1}{c}{ Assets } & \multicolumn{1}{c}{ Liabilities } \\
\hline Risky Assets - Interbank Loan: $a_{t}-i_{t}$ & Long-term Liabilities: $l$ \\
\hline Interbank Loan: $i_{t}$ & Equity Capital: $c$ \\
\hline Reserves: $k_{s, t}$ & \\
\hline
\end{tabular}

The interbank loan pays a gross interest rate of $\rho$, which is proportional to the additional leverage the interbank loan generates, thereby accounting for the increased risk that the risky bank is going to default. Specifically,

$$
\rho=1+\rho_{0} \times \frac{i_{t}}{a_{t}}
$$

where $\rho_{0}$ is a scaling factor.

The level of capital reserves that the central bank requires the commercial banks to maintain corresponds to a certain proportion of the value of risky assets that they hold, and is stipulated in the form a total regulatory capital ratio, $\kappa$.

Issuing an interbank loan is equivalent to reallocating endowment capital from risky assets to the interbank market, without changing the overall size of the prudent bank's balance sheet. Borrowing in that market increases the size of the risky bank's balance sheet. As a result, the levels of capital reserves held by the two banks after the transaction will differ, as shown in equations (3.2) and (3.3) for the prudent and the risky bank respectively.

$$
\begin{gathered}
k_{s, t}=\kappa \times\left[\left(a_{t}-i_{t}\right)+i_{t}\right]=\kappa a_{t} \\
k_{u, t}=\kappa \times\left(a_{t}+\frac{1}{1+\kappa} i_{t}\right)
\end{gathered}
$$


The investment payoffs to the banks differ and realise consecutively. The payoff to the risky bank realises first at $t=1$, while that to the prudent one realises immediately afterwards at $t=2$.

The payoffs of the risky bank $\widetilde{R_{H}}$, and the prudent bank $\widetilde{R_{L}}$ are given by:

$$
\begin{gathered}
\widetilde{R_{H}}=\left\{\begin{array}{c}
R_{H} \text { with probability } p\left(S_{H}\right) \\
0 \text { with probability } 1-p\left(S_{H}\right)
\end{array}\right. \\
\widetilde{R_{L}}=\left\{\begin{array}{c}
R_{L} \text { with probability } p\left(R_{L} \mid R_{H}\right)=1 \\
R_{L} \text { with probability } p\left(R_{L} \mid 0\right)=p\left(S_{L}\right) \\
0 \text { with probability } 1-p\left(S_{L}\right)
\end{array}\right.
\end{gathered}
$$

where $R_{H}$ and $R_{L}$ are the gross rates of return on the investments of the risky bank and the prudent bank respectively, $R_{H}>R_{L}, p\left(S_{H}\right)$ is the unconditional probability of the risky bank's investment project being a success, and $p\left(S_{L}\right)$ is the probability of the prudent bank's project success being conditional on the risky bank's project failing.

This structure leads to three possible states of the economy, according to the three combinations of the unconditional and conditional probabilities of the banks' investment projects being successful. (1) A good state, in which the investments of both banks are successful (unconditional probability of $p\left(S_{H}\right)$ ); (2) a neutral state, in which the investment of the risky bank fails but that of the prudent one is successful (unconditional probability of $\left[1-p\left(S_{H}\right)\right] \times p\left(S_{L}\right)$ ); and (3) an adverse state, in which both investments fail (unconditional probability of $\left[1-p\left(S_{H}\right)\right] \times\left[1-p\left(S_{L}\right)\right]$ ).

Notice that the information revealed at $t=1$ provides only partial knowledge about the exact state of the economy if $\widetilde{R_{H}}=0$. This in turn affects the central bank's policy.

We model the unconditional probability of a good state, $p\left(S_{H}\right)$, explicitly as a logistic function:

$$
p\left(S_{H}\right)=\frac{1}{1+e^{\alpha+\beta a_{t}}}
$$

The initial equal size of the two banks is normalised to 1 . Hence, $a_{t}$ can be expressed in terms of $\kappa$ as $a_{t}=\frac{1}{1+\kappa^{\prime}}{ }^{4}$ and equation (3.6) is equivalent to:

$$
p\left(S_{H}\right)=\frac{1}{1+e^{\alpha+\beta\left(\frac{1}{1+\kappa}\right)}}
$$

where $\alpha$ is an independent factor which determines the probability that the economy will be in a good state, and $\beta$ is a factor capturing the systemic sensitivity of that probability to changes in the level of investment in the risky asset or capital reserves.

The function $p\left(S_{H}\right)$ is concave and decreasing in $a_{t}$, or, equivalently, increasing in $\kappa$. This reflects an important element of prudential regulation, namely that the higher the levels of capital reserves held by financial institutions, the greater the stability and resilience of the financial system.

\footnotetext{
${ }^{4}$ Initially, a bank's asset-side of the balance sheet comprises only risky assets and capital reserves, therefore $a_{t}+\kappa \times a_{t}=1$ or $a_{t}=\frac{1}{1+\kappa}$.
} 
The terminal values of the two banks can be expressed as follows. For the risky bank:

$$
V_{u, T}=\max \left(\left[R_{H}\left(a_{t}+i_{t}\right)-\rho i_{t}+k_{u, t}\right], 0\right)
$$

which takes a value of 0 with unconditional probability $1-p\left(S_{H}\right)$. For the prudent bank:

$$
V_{s, T}=\max \left(\left[R_{L}\left(a_{t}-i_{t}\right)+\rho i_{t}+k_{s, t}\right], 0\right)
$$

which takes a value of 0 with unconditional probability $\left[1-p\left(S_{H}\right)\right] \times\left[1-p\left(S_{L}\right)\right]$.

\section{Non-financial Firms}

The primary role of non-financial firms in the model is to generate real economic output outside the financial system by appropriately investing funds they obtain from the banks in positive net present value investment projects. The non-financial sector is a perfectly competitive environment consisting of two types of firms, higher and lesser creditworthy corporations. Higher (lower) creditworthy firms invest in less (more) risky projects as defined by their unconditional probability of success. These projects generate an average rate of return, $r$. The two banks invest in risky assets by channeling loans to the non-financial firms. A firm's creditworthiness is determined by the bank they borrow from, so the prudent bank channels funds to more creditworthy firms, and vice versa. Accordingly, the probabilities that the investments of the differing credit classes of firms are successful are identical to the banks from which they borrow.

\section{The Central Bank}

The central bank's objective is to maximise the difference between the volume of economic output generated in the system and the expected costs of economic distress. The value function of the central bank incorporates the economic output generated by the financial system and the non-financial firms, the additional costs generated by stress in the interbank market, the opportunity cost of requiring banks to hold capital reserves, output losses resulting from bank failures, the direct costs of assisting a bank in distress, and the expected repayment of any emergency funding it may provide.

\section{Real Economic Activity}

Economic output is generated by the non-financial firms by utilising the funds intermediated by the banks to pursue investments in value-generating projects. The activities of the banks also add value to the economy, hence the net payoffs they earn are also accounted for in the economic output function. The total economic output, $\Omega$, is given by:

$$
\Omega=\left(R_{H}-1\right) \times\left(a_{t}+i_{t}\right)+\left(R_{L}-1\right) \times\left(a_{t}-i_{t}\right)+2 r a_{t},{ }^{5}
$$

\footnotetext{
${ }^{5}$ This is a reduced form of the basic function of economic output specified as $\Omega=\left(R_{H}-1\right) \times\left(a_{t}+i_{t}\right)-$ $(\rho-1) i_{t}+\left(R_{L}-1\right) \times\left(a_{t}-i_{t}\right)+(\rho-1) i_{t}+r\left(a_{t}+i_{t}\right)+r\left(a_{t}-i_{t}\right)$.
} 
A default on a bank's interbank obligations would result in a significant impairment of the functioning of the interbank money market. Given its importance for an efficient transmission of monetary policy, as well as its close relation with the interest rates derivatives market, this will lead to additional costs, $s$, that the central bank has to bear if it does not intervene. In October 2008, during the financial crisis, the LIBOR-OIS spread, often considered to be a gauge of the health and efficient functioning of the interbank market, rose from its pre-crisis average of approximately 10 basis points to more than 350 basis points. Furthermore, the TED spread, measuring the perceived credit risk in the entire economy, increased from approximately 30 basis points to almost 460 basis points during the same period. The magnitude of these changes indicates how substantial the economic costs of a sudden evaporation of confidence in the interbank market can be. Indeed, Brunnermeier and Pedersen (2009) report that while the losses sustained between 2007 - 2008 by U.S. financial institutions alone were in the order of several hundred billion dollars, they were subsequently amplified to more than 8 trillion dollars in the overall stock market. While a central bank's intervention can mitigate these costs, we assume it involves guaranteeing the principal of interbank loan's amount extended, forcing banks to forego any interest they expect to earn on their funding position.

Requiring commercial banks to maintain a certain level of reserves diminishes the amount of capital available for lending to the non-financial firms, thus lowering total economic output, and creating a deadweight loss for the economy. This opportunity cost, denoted by $\Phi$, is modelled as the value of additional output of non-financial firms that is lost every period.

$$
\Phi=r \times\left(k_{s, t}+k_{u, t}\right)=r \times\left(2 a_{t}+\frac{1}{1+\kappa} i_{t}\right) \kappa
$$

The effects of a bank failure are similar in this respect, as they result in a sharp decline in credit supply. We assume that a bank that has been resolved is not replaced in the system. This loss of output, $\Gamma$, is modelled as a perpetuity paying $a_{t} \times r$ every period, that is, the return the non-financial firms could have generated had total credit supply not decreased. Using the average rate of return, $r$, generated by the non-financial firms as a discount factor, the present value of such a perpetuity is simply $\Gamma=a_{t}$.

Finally, any central bank assistance to a bank in distress involves restoring that bank's balance sheet to its initial position. That is, the central bank provides the troubled bank with funds equal to the value of its long-term liabilities and equity capital net of the capital reserves it is required to hold, denoted by $\Lambda$. Since such funds are not a subsidy, the central bank's value function also accounts for the expected value of their repayment, $\Psi=\delta \times \Lambda$, where $\delta$ is a discount factor. Additionally, the central bank may also charge a penalty interest rate, $r_{p}$, on the assistance it provides. As a result, the value function that the central bank maximises is given by:

$$
\mathrm{V}_{\mathrm{CB}}=E[\Omega]-\Phi-E[s]-E[\Gamma]-E[\Lambda]+E[\Psi]
$$


corresponding to the difference between the aforementioned economic gains and costs.

\section{Central Bank's Strategic Policy Objectives}

In order to achieve its policy objective the central bank chooses one of the following three strategies when responding to a crisis in the banking system. First, it may allow a bank in distress to be resolved. Second, it may intervene in the interbank market and guarantee the repayment of any interbank loans in order to prevent stress and contagion, while still allowing the bank in distress to be resolved. Finally, it may attempt to avert a crisis altogether by immediately assisting the bank in distress through an injection of liquidity.

An important assumption is that the extent of the central bank's assistance capacity is restricted to just one bank in the system. This reflects the notion that accepting essentially worthless collateral in return for the support funds it provides leads to a significant deterioration of the overall quality of the assets held on the central bank's balance sheet (Buiter, 2008).

Importantly, in order to fulfil its mandate the central bank always has an incentive to save at least one bank. A failure of both banks leads to a collapse of the entire financial system, and results in an infinitely large economic loss.

\section{Structure and Evolution of the Game}

At $t=0$ the central bank selects one of the three potential strategies outlined above. This decision is based on maximising the expected value of its value function for each strategy. This decision is then publicised and becomes common knowledge. The commercial banks determine the size of the interbank loan that maximise their expected terminal value given the central bank's policy. The gross interest rate $\rho$ is specified, the transaction in the interbank market takes place, and the two banks make their investments.

Between $t=0$ and $t=1$ a shock determining the state of the economy occurs, and $R_{H}$ realises at $t=1$. If $R_{H}=R_{H}$, then $R_{L}=R_{L}$ in the subsequent period. In that case, both banks earn their expected returns, the risky bank repays the interbank loan together with the interest that it owes, and the central bank does not have to intervene, nor incurs any losses.

If the realisation of $R_{H}$ at $t=1$ is $R_{H}=0$, the value of the risky bank's assets reduces to 0 , and the path along which the subsequent events in the game evolve depends upon the strategy that the central bank has adopted. If the central bank decides not to respond to the failure of the risky bank's investment and allows the bank to be resolved, it incurs the cost associated with the loss of future output, together with the costs associated with the ensuing stress in the interbank market, so that:

$$
\mathrm{L}_{\mathrm{CB}, \mathrm{t}=1}=\Gamma+s
$$

The latter cost can be mitigated if the central bank restricts its intervention to guaranteeing the interbank loan. Such a decision, however, implies that it incurs an additional cost equal to the value of the principal amount of the interbank loan, that is: 


$$
\mathrm{L}_{\mathrm{CB}, \mathrm{t}=1}=\Gamma+i_{t}
$$

Finally, the central bank can avoid incurring the cost of future output loss altogether by assisting the risky bank and providing it with enough capital to restore its balance sheet to its initial position while still guaranteeing its interbank obligations. The cost of such intervention is equal to the value of the bank's longterm liabilities and equity capital, net of the reserves it holds, so that:

$$
\mathrm{L}_{\mathrm{CB}, \mathrm{t}=1}=l+c+i_{t}-k_{u, t}
$$

Using the balance sheet identity equation ${ }^{6}$, and substituting $k_{u, t^{7}}$ the above cost becomes:

$$
\mathrm{L}_{\mathrm{CB}, \mathrm{t}=1}=a_{t}+\frac{1}{1+\kappa} i_{t}
$$

The events at $t=2$ depend on both the realisation of $R_{L}$ and the actions of the central bank at $t=1$. If the prudent bank earns the expected return on its investment but the central bank does not take any action at $t=1$, it is forced to write off its interbank position. If size of the interbank loan is large enough, writing it off will put the prudent bank in distress. The sufficient condition for distress to occur is for the value of the interbank loan to be greater than the net return the bank earns on its risky assets, namely: ${ }^{8}$

$$
\frac{\mathrm{R}_{\mathrm{L}}-1}{R_{L}} a_{t}<i_{t}
$$

If equation (3.17) holds, the central bank must provide the prudent bank with a capital injection equal to the value of the interbank loan less the net return the prudent bank earns, so that:

$$
\mathrm{L}_{\mathrm{CB}, \mathrm{t}=2}=i_{t}-\left(R_{L}-1\right) \times\left(a_{t}-i_{t}\right)
$$

In the adverse state of the economy, when $R_{L}=0$, the central bank provides the prudent bank with enough capital to restore its balance sheet to its initial position, that is:

$$
\mathrm{L}_{\mathrm{CB}, \mathrm{t}=2}=l+c-k_{s, t}
$$

or:

$$
\mathrm{L}_{\mathrm{CB}, \mathrm{t}=2}=a_{t}
$$

The central bank's decision to guarantee the risky bank's obligations in the interbank market means that a part of the emergency capital injection the prudent bank requires in a bad state of the economy has already been provided at $t=1$, changing the cost of assistance to:

\footnotetext{
${ }^{6}$ Based on the initial balance sheet, $l+c=a_{t}+\kappa a_{t}$.

${ }^{7} k_{u, t}=\kappa \times\left(a_{t}+\frac{1}{1+\kappa} i_{t}\right)$.

${ }^{8}$ This is a reduced form of the inequality $\left(R_{L}-1\right) \times\left(a_{t}-i_{t}\right)<i_{t}$.

${ }^{9}$ If this inequality does not hold, the prudent bank will be able to write off the interbank loan, and is not going to require any assistance from the central bank.
} 


$$
\mathrm{L}_{\mathrm{CB}, \mathrm{t}=2}=a_{t}-i_{t}
$$

Finally, the prudent bank is resolved in a bad state of the economy if the central bank decides to fully assist the risky bank at $t=1$. This situation arises as the central bank has insufficient funds left to assist the prudent bank. Figure 1 depicts all the possible sequences of events, together with the costs that the central bank incurs in each state of the economy, as well as the payoffs to the two banks.

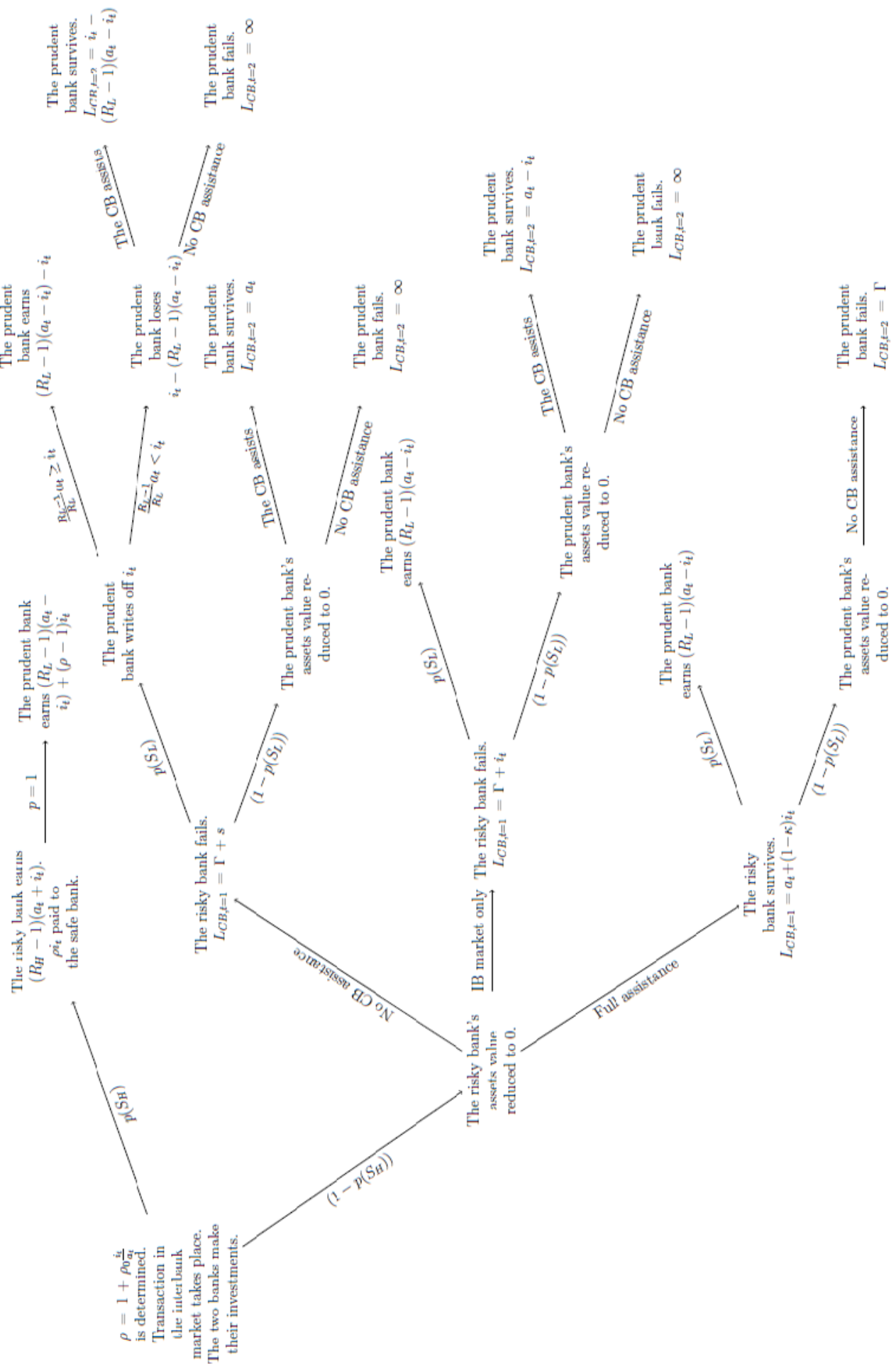

Figure 1: Event Tree 


\section{Solving the Model}

To derive the optimal central bank policy we simulate the interactions in the model for plausible values of the specified parameters which we justify below. This approach also allows us to identify key decision-relevant factors for the central bank. Given the central bank's crisis response strategy chosen and publicised at $t=0$, it is possible to identify the size of the interbank loan that maximises the terminal values of the two banks. We first derive the expected terminal values of the two banks for each of the three strategies, and then take first derivatives with respect to the size of the interbank loan. ${ }^{10}$

The results for the risky bank show that the optimal size of the interbank loan is constant regardless of the strategy selected by the central bank, and is given by:

$$
i_{u, t}=\frac{R_{H}+\kappa}{2 \rho_{0}(1+\kappa)^{2}}
$$

The optimal size of the interbank loan for the risky bank depends positively on the level of returns it expects to earn, $R_{H}$, and is negatively related to the cost of borrowing in the interbank market, $\rho_{0}$, and the level of capital reserves, $\kappa$, the bank is required to maintain.

In the case of the prudent bank, the optimal size of the interbank loan it extends depends upon the strategy selected by the central bank. If the central bank decides on a non-intervention strategy at $t=1$, this has different consequences for the prudent bank, depending on the relation between the size of the interbank loan and the prudent bank's net earnings.

When the size of the interbank loan exceeds the net earnings of the prudent bank, $\frac{R_{L}-1}{R_{L}} a_{t}<i_{t}$, the terminal value-maximising loan size function is given by:

$$
i_{s, t}=\frac{R_{L}-1}{2 \rho_{0}(1+\kappa)}
$$

For $\frac{R_{L}-1}{R_{L}} a_{t} \geq i_{t}$, the loan size function is given by:

$$
i_{s, t}=\frac{R_{L}\left[p\left(S_{H}\right)+p\left(S_{L}\right)-p\left(S_{H}\right) p\left(S_{L}\right)\right]+\left[p\left(S_{L}\right)-p\left(S_{H}\right)-p\left(S_{H}\right) p\left(S_{L}\right)\right]}{2 p\left(S_{H}\right) \rho_{0}(1+\kappa)}
$$

In the adverse state of the economy, the terminal outcome for the prudent bank depends upon which of the remaining two strategies the central bank selects. However, as the repayment of the principal amount of the loan is guaranteed under either strategy, the loan size maximising the prudent bank's terminal value is the same in both cases, and is given by:

$$
i_{s, t}=\frac{\left(R_{L}-1\right)\left[p\left(S_{H}\right)+p\left(S_{L}\right)-p\left(S_{H}\right) p\left(S_{L}\right)\right]}{2 p\left(S_{H}\right) \rho_{0}(1+\kappa)}
$$

The prudent bank's decision depends not only on the factors that also drive the decision of the risky bank, but are additionally impacted by the probabilities that

\footnotetext{
${ }^{10}$ For details see Appendix A.
} 
determine the state of the economy. Irrespective of which crisis response strategy the central bank selects, the optimal size of the interbank loan for the prudent bank is related to the level of expected return on its investment, $R_{L}$, the cost of borrowing in the interbank market, $\rho_{0}$, and the level of capital reserves, $\kappa$, in an identical fashion as the size of the interbank loan for the risky bank. However, in case of the strategies in which the repayment of the interbank loan is guaranteed by the central bank, the size of the interbank loan for the prudent bank also depends negatively on the unconditional probability that the economy will be in a good state, $p\left(S_{H}\right)$, and positively on the difference between the sum and the product of the two probabilities in the model.

An important constraint is that the risky bank cannot borrow more than the prudent bank is willing to lend, and vice versa. Thus, the actual size of the interbank loan is given by the minimum of the two optimal individual size functions:

$$
i_{t}=\min \left(i_{s, t}, i_{u, t}\right)
$$

This mechanism also ensures that the expected terminal value of at least one of the two banks is maximised. The intersection of the two loan size functions corresponds to a simultaneous maximisation of their expected terminal values.

\section{Simulation Experiments}

The value of the functions described in the preceding section depend upon a number of fixed parameters together with the total capital ratio, $\kappa$, which can take any value between 0 and 1 . In all the simulations below, the total capital ratio is treated as the independent variable. ${ }^{11}$

\section{Baseline Simulation}

Table 2 lists the selected parameter values for the baseline simulations. These values are chosen to constitute a reasonable reflection of those encountered in developed economies. Specifically, performance-related information available via Bloomberg Database and the FRED Database indicates that more risky banks have been generating return on equity in excess of $25 \%$, while the safer ones of approximately $10 \%$. We believe our assumed parameter values for $R_{H}$ and $R_{L}$ are, therefore, quite conservative. As reported by Damodaran (2015), the average annual rate of return of S\&P 500 listed firms between 1928 and 2014 is approximately 10\%, justifying our choice of the value for $r$. The choice of parameters $\alpha$ and $\beta$ results in a probability of a successful investment by the risky bank of between $62.5 \%-67.5 \%$, reflecting the average cumulative five-year survival probability of a B-rated corporation (Hamilton and Cantor, 2006). Given the assumption about $R_{L}$, the likelihood of the prudent bank's success conditional on the risky one's failure, $p\left(S_{L}\right)$, reflects its greater financial soundness and resilience. This difference in the banks' risk profiles is further reflected in the values assigned to their respective discount factors, $\delta_{s}$ and

${ }^{11}$ All the simulations presented in this paper were undertaken using MatLab. 
$\delta_{u}$, which mirror the cost of equity capital reported by real banks. Finally, the choice of the value for $s$ pertains to Brunnermeier and Pedersen's (2009) analysis of the 2007 - 2008 liquidity crunch, in which the initial losses of the financial sector were reported to be approximately $5 \%$ of stock market capitalisation. Our assumption of $s=0.1$ thus corresponds to $5 \%$ of the total initial value of the commercial banking system in the model.

Fixed parameter values for the baseline simulations

Table 2

\begin{tabular}{cc}
\hline Parameter & Assumed value \\
\hline$R_{H}$ & 1.2 \\
$R_{L}$ & 1.05 \\
\hline$r$ & 0.1 \\
\hline$\rho_{0}$ & 0.5 \\
\hline$\alpha$ & -1 \\
\hline$\beta$ & 0.5 \\
\hline$p\left(S_{L}\right)$ & 0.7 \\
\hline$\delta_{s}$ & 0.75 \\
\hline$\delta_{u}$ & 0.2 \\
\hline$s$ & 0.1 \\
\hline$r_{p}$ & 0 \\
\hline
\end{tabular}

\section{The Interbank Loan Market}

If the value of the interbank loan is lower than the net earnings of the prudent bank, $\frac{R_{L}-1}{R_{L}} a_{t} \geq i_{t}$, the prudent bank is able to absorb the losses suffered in the interbank market when the risky bank defaults on its loan obligations.

Figure 2 depicts the simulated optimal loan size, defined as that which maximises a bank's expected terminal value for a given level of capital reserve requirements and the loan size limit implied by the inequality in (3.17). 


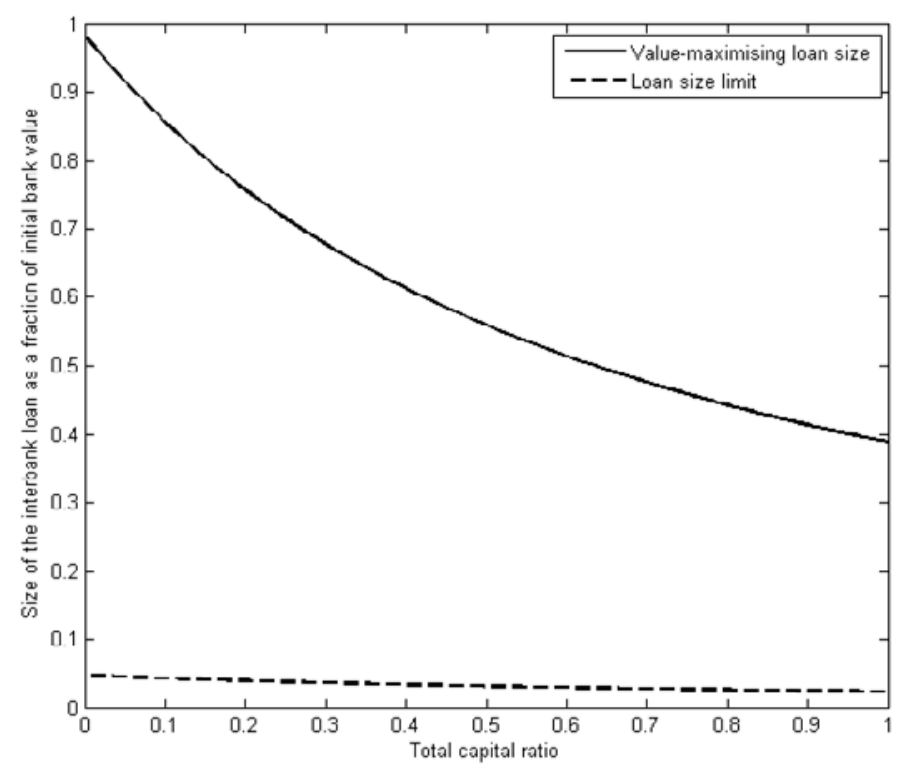

Figure 2: Optimal loan size for the prudent bank, subject to $\frac{R_{L}-1}{R_{L}} a_{t} \geq i_{t}$

The baseline results show that the prudent bank's optimal loan size exceeds the limit implied by its net earnings, and indeed that the difference between the two is substantial. We find that $\rho_{0}$, interpreted as the sensitivity of the net interest rate on the interbank loan to the amount of additional leverage the loan creates, must increase from its baseline value of 0.5 to almost 10 , ceteris paribus, for $\frac{R_{L}-1}{R_{L}} a_{t} \geq i_{t}$ to hold. This implies that the net interest rate on a loan which increases the leverage of the risky bank by 1 percentage point should be $10 \%$. Such degree of sensitivity, however, makes borrowing in the interbank market prohibitively expensive.

The results for the case of $\frac{R_{L}-1}{R_{L}} a_{t}<i_{t}$ are shown in Figure 3 . Here the inequality holds, as the optimal loan size is above the limit implied by the prudent bank's net earnings. The conclusions for the situation where $\frac{R_{L}-1}{R_{L}} a_{t} \geq i_{t}$ also apply in this case, as increasing $\rho_{0}$ reduces the optimal loan size. 


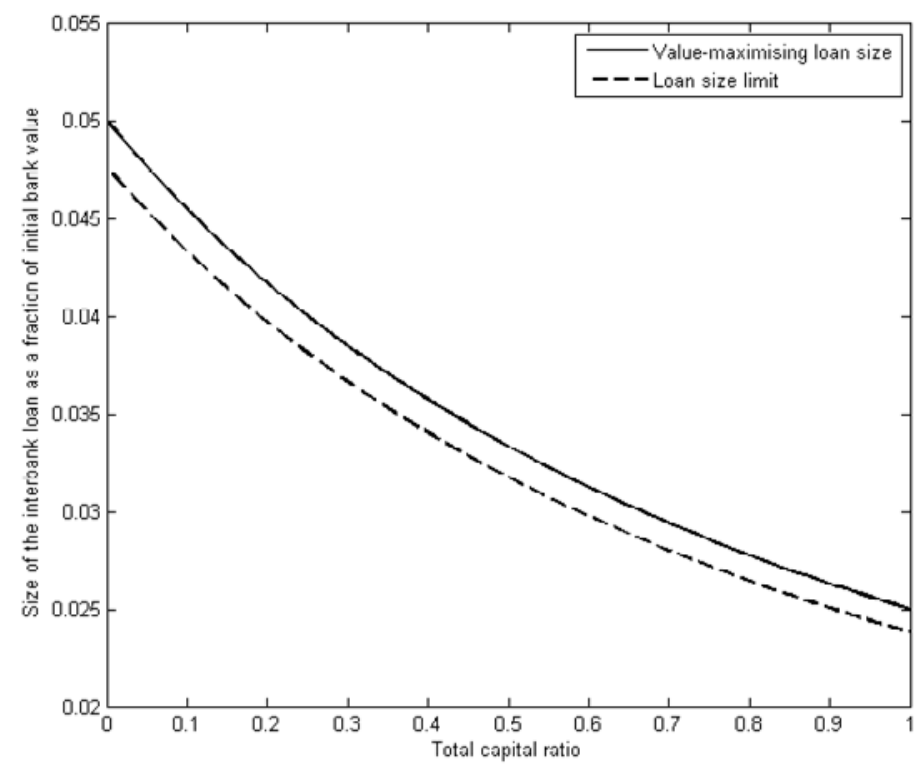

Figure 3: Optimal loan size for the prudent bank, subject to $\frac{R_{L}-1}{R_{L}} a_{t}<i_{t}$

Collectively, the two results illustrated in Figures 2 and 3 indicate that the prudent bank is able to absorb any losses in the interbank market only if the volume of lending in this market is small. Hence, we conclude that in a majority of cases, if the central bank does not act at $t=1$, the prudent bank will always require its assistance at $t=2$. This implies that its optimal loan size in this case is given by equation (3.23), and by equation (3.25) if the central bank decides to act.

We determine the volume of interbank market transaction, $i_{t}=\min \left(i_{s, t}, i_{u, t}\right)$, by comparing the prudent bank's optimal loan size functions with the amount the risky bank wishes to borrow. These are depicted in Figure 4.

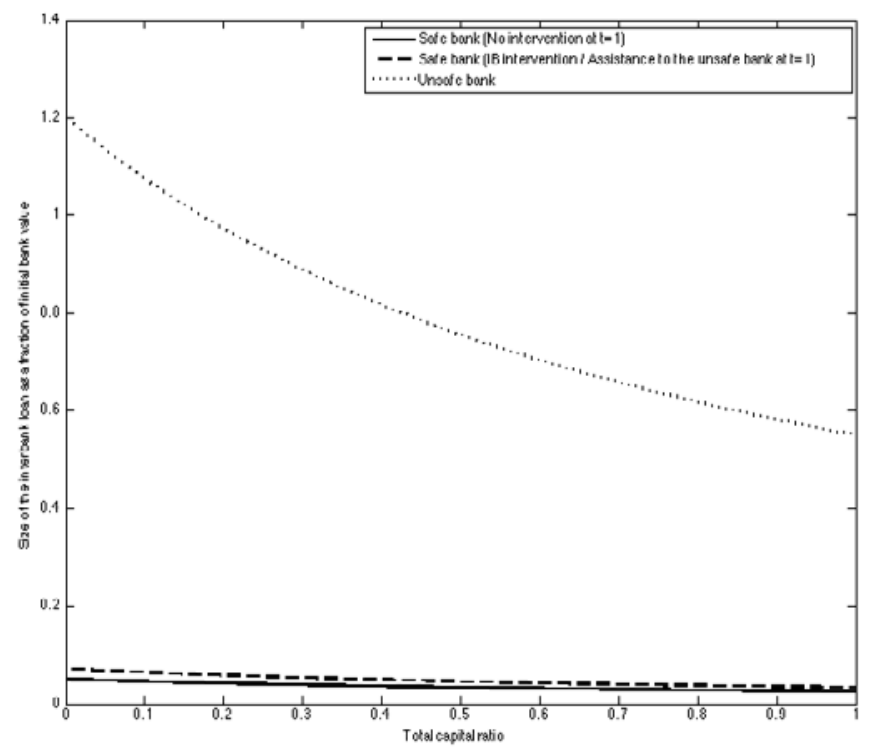

Figure 4: The optimal loan size functions of the prudent and the risky bank 
Figure 4 confirms that for a plausible range of parameters, the size of the loan issued in the interbank market is always equal to that which maximises the expected terminal value of the prudent bank, $i_{t}=\min \left(i_{s, t}, i_{u, t}\right)=i_{s, t}$. Indeed, we find that the two banks maximise their expected terminal values simultaneously only when $R_{H}$ is reduced to a level very close to $R_{L}$ and $\rho_{0}$ is also substantially decreased.

\section{The Central Bank's Value Function}

We present the baseline results for the central bank's value function for the three defined strategies in Figure 5.

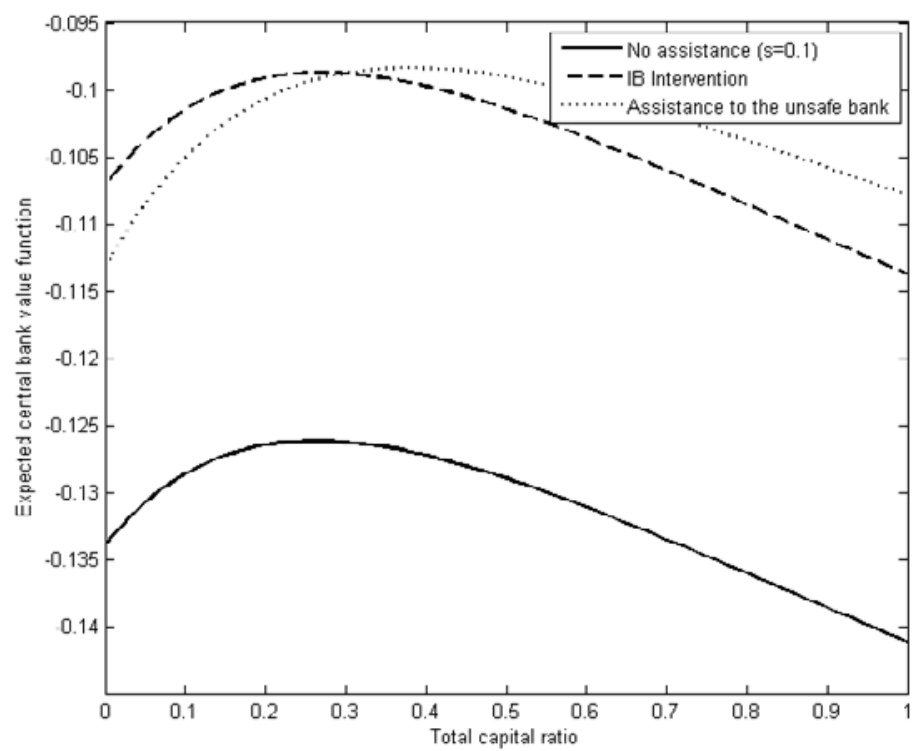

Figure 5: Baseline results for the central bank's strategies

The central bank's expected value function for all three strategies is convex, implying there exists an optimal level of capital requirements which maximises its objective function in all cases. Each function is also asymmetric, with marginal benefits accruing from increasing capital requirements towards their optimal level greater than the marginal costs of increasing them beyond it. Moving towards that optimal level, however, yields diminishing marginal benefits in each case.

Figure 5 suggests that a strategy of no intervention at $t=1$ generates the worst policy outcome for the central bank. Note that this result is sensitive to the assumption that the economy incurs additional costs arising from stress in the interbank market which may impair the efficiency of the monetary transmission mechanism. We find that if this cost is minimal $(s=0)$ this strategy actually becomes the most preferable option for the central bank, a result illustrated in Figure 6a. Furthermore, as shown in Figures $6 \mathrm{~b}$ and $6 \mathrm{c}$, we identify $s=0.03$ and $s=0.045$ as critical levels of that cost, changing the central bank's preference for one strategy over the remaining two. These results indicate that the introduction of an alternative mechanism supporting the efficient functioning of the interbank market in crisis conditions, other than an explicit guarantee of interbank loan repayments, would affect the central bank's strategic policy preferences. The regulatory liquidity standards introduced in the Third Basel Accord, requiring financial institutions to hold enough highly-liquid assets to meet their short-term 
financing needs in stressed market conditions, are one example of a mechanism which could help to reduce the costs generated by an impairment of the interbank market's functioning during a crisis.

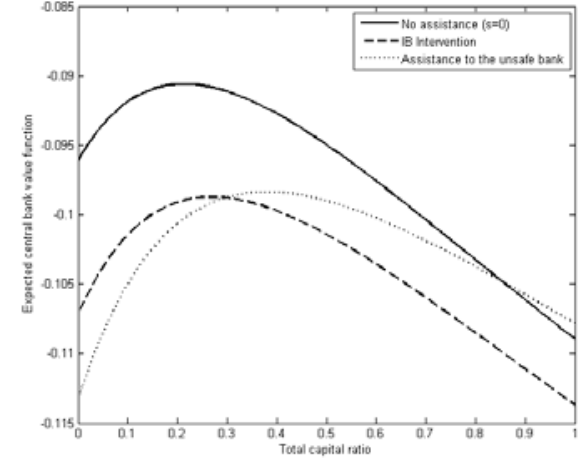

(a) $s=0$

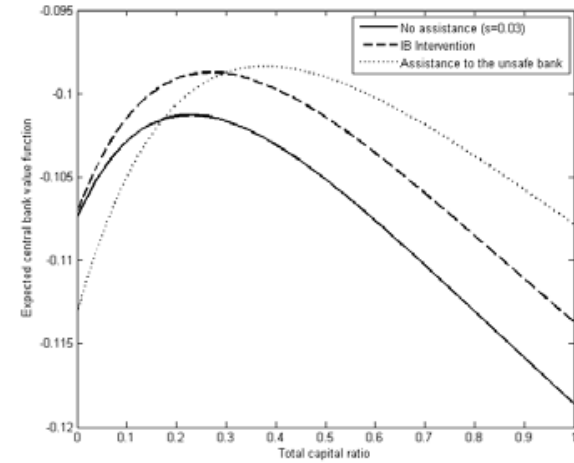

(b) $s=0.03$

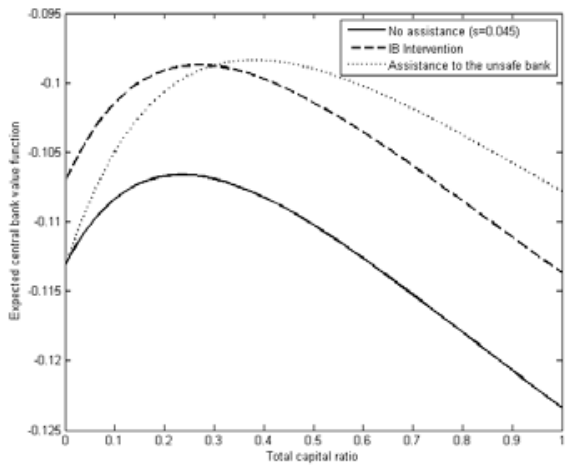

(c) $s=0.045$

Figure 6: Expected central bank's value function for different level of $s$

Figure $6 c$ demonstrates that the additional cost of $s=0.045$ is sufficient to make the outcome of the strategy of no assistance at $t=1$ worse than those in which the central bank guarantees the repayment of the interbank loan. For that reason, we consider this strategy is likely to be inferior to the remaining two.

We compare the baseline results for central bank intervention in the interbank market at $t=1$ to guarantee the interbank loans, with further assisting the risky bank by restoring its balance sheet in Figure 7 . 


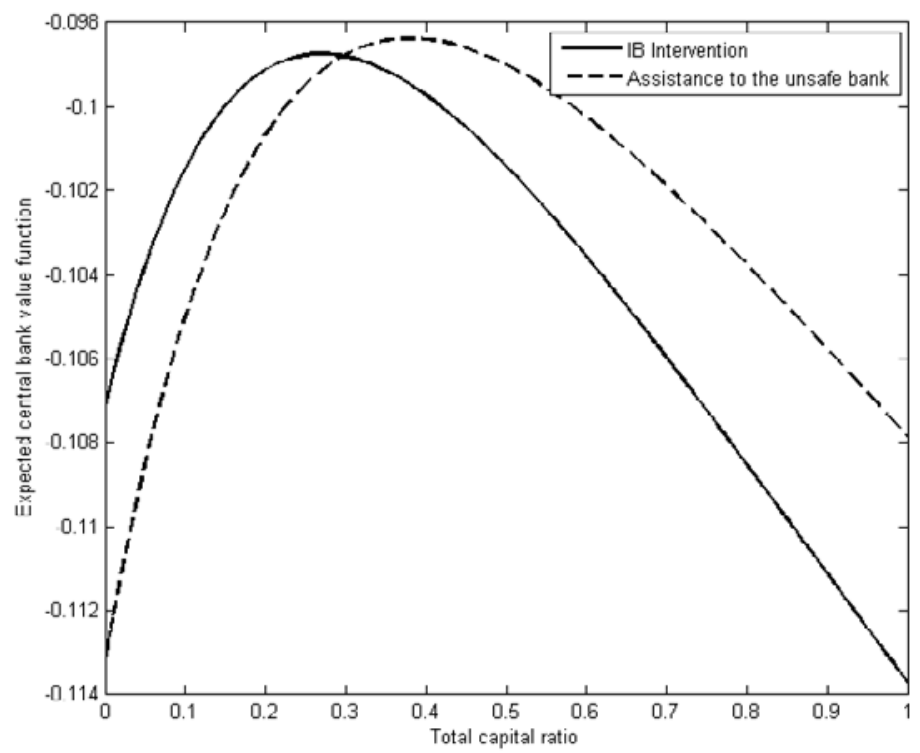

Figure 7: Effects of loan guarantee intervention in the interbank market, compared with providing full assistance to the risky bank at $t=1$

Restoring the balance sheet of the risky bank at $t=1$ leads to a superior outcome for the central bank, as its expected value function is maximised at a higher level. This, however, is achieved for a level of capital requirements that is approximately 15 percentage points higher than in the situation where central bank intervention is restricted to guaranteeing loans in the interbank market. In effect, the capital reserves of the risky bank must be sufficiently high, thereby serving to at least partially counterbalance its riskiness in order for the central bank to find it optimal to provide balance sheet assistance.

This preference for assisting the risky bank arises for two reasons. First, even though the central bank guarantees the repayment of the principal amount of the interbank loan in both strategies, it expects the risky bank to eventually repay any assistance it receives. ${ }^{12}$ If, however, the central bank only intervenes in the interbank market to guarantee loans, that amount of assistance becomes a pure loss. Second, the schedule of costs incurred by the central bank in each of the two strategies is different. The costs of assisting the risky bank which are incurred at $t=1$ are lower than those of intervening in the interbank market. ${ }^{13}$ Although interbank market intervention results in a smaller loss at $t=2$, this loss is only incurred in the adverse state of the economy. Consequently, the degree to which the $t=2$ loss affects the central bank's expected value function and its strategic preferences depends on the unconditional probability of the occurrence of an adverse state.

Modifying the assumptions about the parameter values determining the size of the interbank loan $\left(\rho_{0}\right)$, and the unconditional probability of the adverse state of the economy $\left(p\left(S_{L}\right)\right)$ has implications for the central bank's preference for one strategy

${ }^{12}$ The discount factors applied to the repayment of emergency funding provided to a commercial bank reflect both the probability of repayment and the time a bank will require to return the funds.

${ }^{13}$ Intervention in the interbank market: $L_{C B, t=1}=a_{t}+i_{t}$ at $t=1$, and $L_{C B, t=2}=a_{t}-i_{t}$ at $t=2$; Assisting the risky bank: $L_{C B, t=1}=a_{t}+(1-\kappa) i_{t}$ at $t=1$, and $L_{C B, t=2}=a_{t}$ at $t=2$. 
over the other. Figures 8 and 9 depict the effects of reducing the size of the interbank loan, and of increasing the unconditional probability of the adverse state, respectively. Both modifications make intervening in the interbank market to guarantee the loan repayments the strategy which results in the best outcome for the central bank. A lower volume of interbank lending reduces the costs of assisting the bank in distress, as well as the pure loss the central bank incurs if it guarantees the loan repayment, thereby increasing the maximum value of the expected central bank value function and reducing the optimal level of capital requirements.

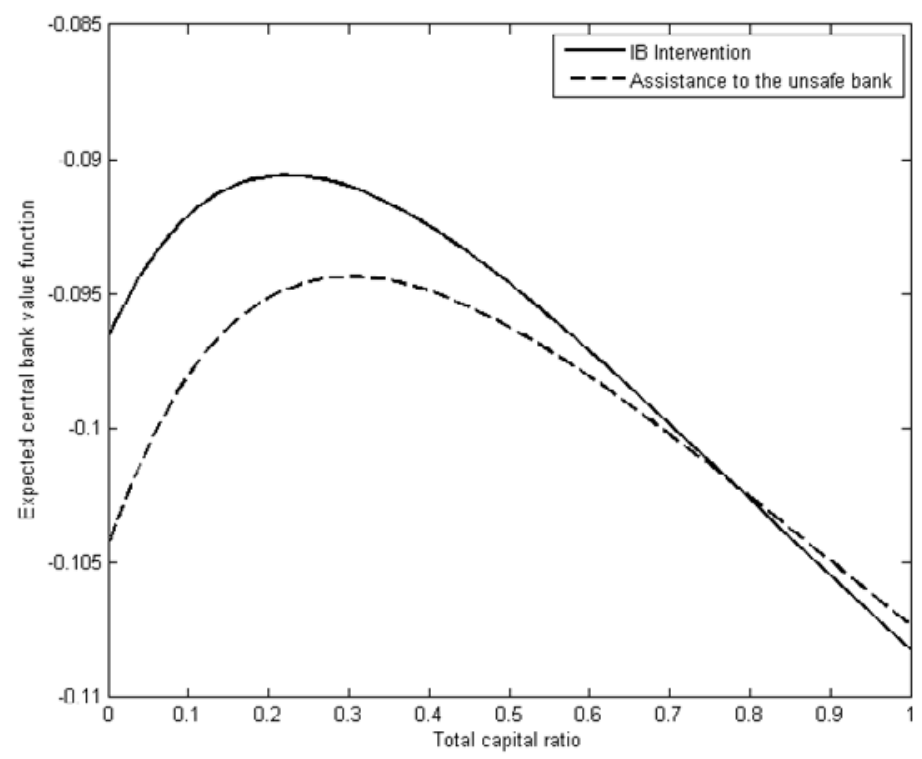

Figure 8: Expected central bank value function based on a smaller interbank loan $\left(\rho_{0} \uparrow\right)$

Conversely, a higher probability of an adverse state of the economy increases the costs the central bank expects to incur. This leads to a higher optimal level of capital requirements. However, the maximum value of the expected central bank value function decreases by less if it confines its intervention to the interbank market, as the $t=2$ loss associated with this strategy is lower than that resulting from assisting the risky bank instead. 


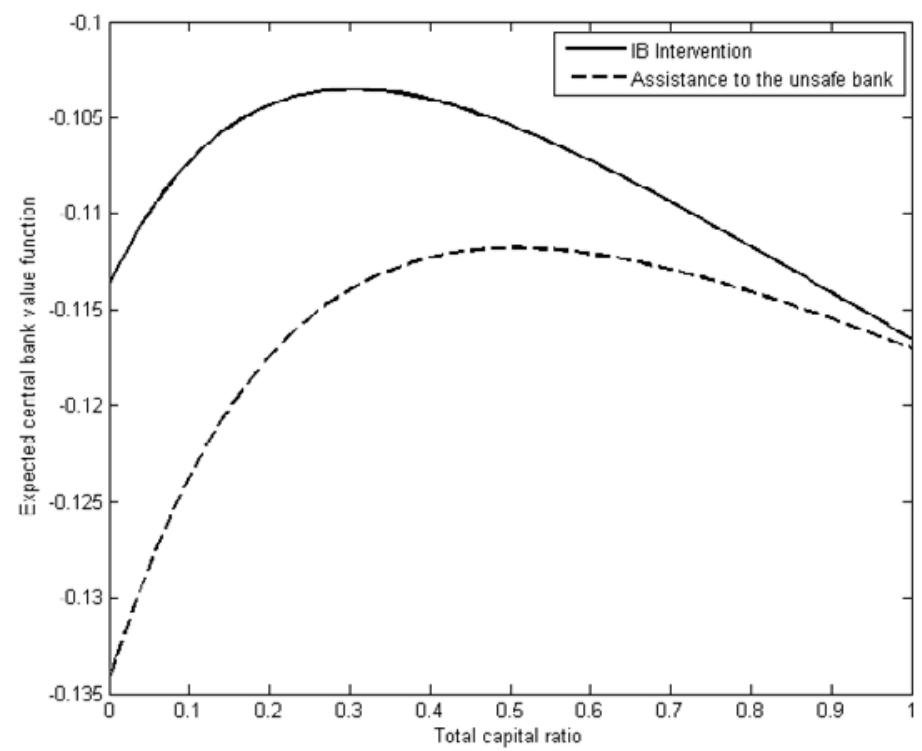

\section{Figure 9: Expected central bank value function based on a higher unconditional} probability of a bad state of the economy $\left(p\left(S_{L}\right) \downarrow\right)$

We also identify the central bank's perception of bank riskiness to be an important factor in determining its preferred strategy. The discount factor applied to the repayment of the emergency funding reflects both the time necessary to return the funds provided by the central bank, as well as the default risk of the assisted institution. If the central bank perceives the risky bank to be even riskier than it is in the baseline simulation, the discount factor (discount rate) applied to it will be lower (higher).

We find that changing the discount factor's value from $\delta_{u}=0.2$ to $\delta_{u}=0.15$ is sufficient for the intervention in the interbank market to become the strictly dominant strategy, a result we illustrate in Figure 10. This implies that the central bank will opt for the safer alternative of intervening in the interbank market and assisting the prudent bank if it believes that the risky bank is likely to default in the future despite receiving emergency funding, or that it will require a very long time to return the funds provided. 


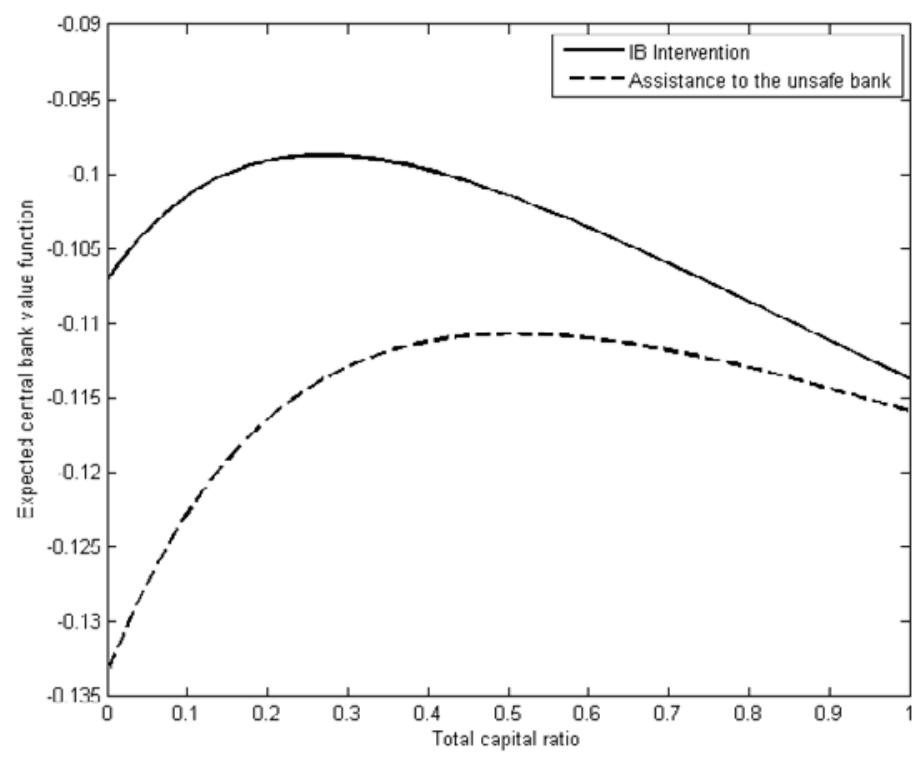

Figure 10: Expected central bank value function based on a lower risky bank's discount factor $\left(\delta_{u} \downarrow\right)$

Finally, the central bank may also consider charging a penalty rate, corresponding to additional interest the assisted institution has to pay on the funds provided. This is illustrated in Figure 11.

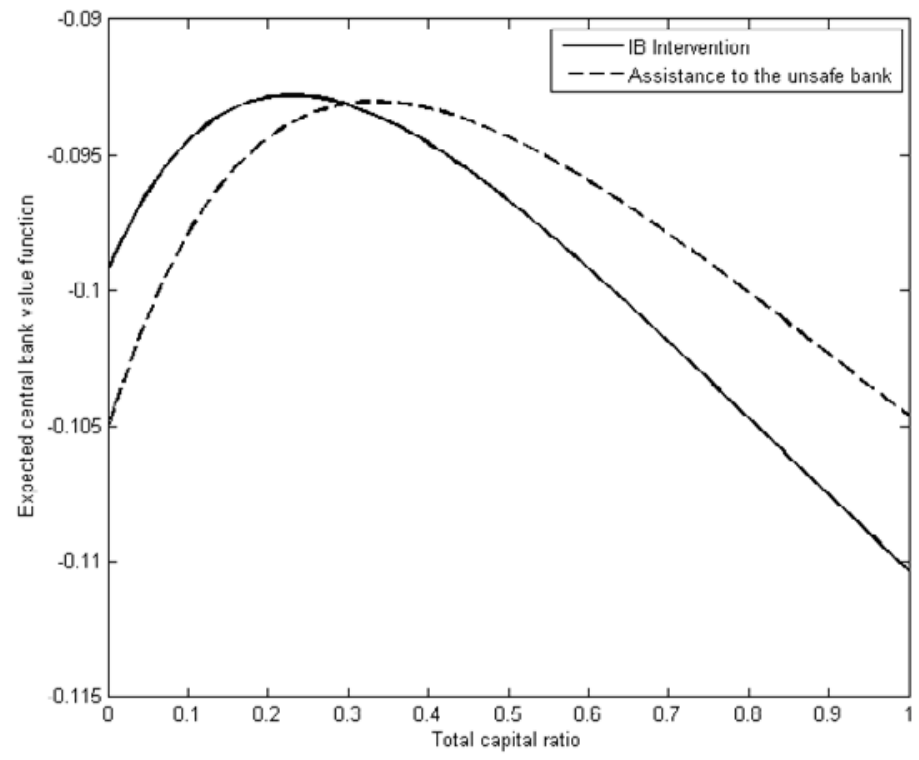

Figure 11: Expected central bank value function with an additional penalty rate on liquidity assistance

The simulation results show that introducing a penalty rate on emergency liquidity assistance increases the maximum values of the central bank's objective function, and lowers the optimal level of capital requirements. Moreover, it also serves to make intervention in the interbank market more likely to be the preferable strategy for the central bank. Effectively, the additional funds the central bank 
expects to receive compensate it for the losses it incurs guaranteeing the principal of the interbank loan, and thus impacts upon the ordering of its preferences.

\section{Comparative Statics}

Table 3 below produces comparative statics showing how the nature of the central bank's expected value function, and the optimal level of the capital requirements change when the assumptions concerning the levels of the fixed parameters are increased.

\section{Comparative statics}

Table 3

\begin{tabular}{ccc}
\hline Change in value assumption & $E\left[V_{C B}\right]$ & $\kappa$ maximising $V_{C B}$ \\
\hline$R_{H} \uparrow$ & $\uparrow$ & $\downarrow$ \\
$R_{L} \uparrow$ & $\uparrow$ & $\downarrow$ \\
$r \uparrow$ & $\uparrow$ & $\downarrow$ \\
\hline$\rho_{0} \uparrow$ & $\uparrow$ & $\downarrow$ \\
\hline$\alpha \uparrow$ & $\uparrow$ & $\downarrow$ \\
$\beta \uparrow$ & $\downarrow$ & $\uparrow$ \\
\hline$\left(S_{L}\right) \uparrow$ & $\uparrow$ & $\downarrow$ \\
\hline$\delta \uparrow$ & $\uparrow$ & $\downarrow$ \\
\hline$s \uparrow$ & $\downarrow$ & $\uparrow$ \\
\hline$r_{p} \uparrow$ & $\uparrow$ & $\downarrow$ \\
\hline
\end{tabular}

The effects of modifying parameters $\rho_{0}, \delta$, $s$, or $r_{p}$ are discussed in detail in the preceding subsection. Increasing $R_{H}, R_{L}$, or $r$ all influence the central bank's value function in the same way. They all lead to a higher expected economic output without changing the central bank's expected losses. These expected gains and losses, however, also depend on the probabilities determining the state of economy. Increasing $\alpha$ and $p\left(S_{L}\right)$ raises the unconditional probabilities of the economy being in a good or a neutral state, in which the investments of the banks are successful. If the probability that the economy is in a good state is more sensitive (higher $\beta$ ) to the amount of reserves held by banks, then the optimal level of capital requirements is also going to be higher. However, this results in a larger opportunity cost of regulation, thus reducing the maximum value of the central bank's objective function.

\section{Discussion}

We believe the predictions arising from the model we outline have a number of important implications for a central bank's financial stability policy design. Crucially, our results emphasise the importance of a central bank's proactiveness in achieving the objectives of a macroprudential financial policy. Positioned at an intersection of financial markets and the real economy, central banks can identify adverse changes in the condition of the financial system, here reflected in interbank market 
conditions, faster than other market participants or policymakers, and gauge their impact on the real economy more accurately. As reflected by the policy implications discussed below, this superior information plays a key role in determining the appropriate design of a central bank's policy.

First, our results imply there is a trade-off between the nature and scope of a central bank's response to a banking crisis, and the level of capital reserves financial institutions are required to hold. A bank's risk appetite is affected both by its assistance expectations, and by the capital requirements with which it has to comply. The absence of an implicit guarantee that the central bank will help in a crisis enhances market discipline, while high capital requirements make riskier investment more costly.

We find that the optimal level of capital requirements increases with the scope of the central bank's commitment to intervene at $t=1$. The baseline results show that the central bank's expected value function is maximised at a lower level of capital reserves when it only intervenes in the interbank market than if it assists the risky bank by restoring its balance sheet. This suggests that financial stability policy should be based on active management of assistance expectations, and setting capital requirements accordingly. Our model shows that a strict commitment to limiting the scope of the central bank's intervention in response to a crisis and requiring financial institutions to hold high capital reserves may be economically wasteful.

Further, as shown in Figure 7, when comparing the effects of interbank loan guarantee intervention and of providing full assistance to the risky bank at $t=1$, there exists a level of regulatory capital requirements at which the value functions associated with the two strategies intersect. At the switch level of capital reserves, the central bank considers the two alternative strategies to be equally effective in achieving its objective. Importantly, this has further consequences for the central bank's policy decision if the regulatory bank capital reserves ratio is set at a different level to that which maximises its value function. Should the specified level of capital reserves be sufficiently greater (lower) than the one for which the two value functions intersect, the central bank can increase the expected value of its policy pre-commitment by a prior commitment to an alternative intervention policy instead. For example, the central bank can achieve a better outcome by announcing a commitment to providing full assistance to the risky bank rather than by limiting its intervention to interbank loan guarantee if the regulatory capital reserves the commercial banks need to hold exceed the level for which it is indifferent between the two strategies, and vice versa. Since the individual sizes of the interbank loans that maximise the expected terminal values of the two commercial banks are the same for each of the two strategies, such decision would not affect their investment policy but would result in a better expected outcome for the entire economic system. While an accurate identification of the preference switch level of regulatory capital may be difficult in practice due to the uncertainty in measuring or estimating variables determining the expected central bank value function, as long as the levels of reserve requirements that maximise the two expected value functions are of a similar order of magnitude, the potential welfare loss stemming from a commitment to a suboptimal intervention policy is not substantial. This uncertainty also implies that the central bank's preference for one strategy over the other may be affected by the reputation it wishes to uphold. 
Second, the results support the use of countercyclical capital buffers. The optimal level of capital requirements is an indicator of the relative importance of bank reserves given the set of conditions assumed in the simulation. Our results show that the significance of capital buffers in enhancing the central bank's value function increases with the unconditional probability of a bad state of the economy, irrespective of how the central bank responds to a crisis. Since banks have no access to external financing, the higher capital requirements in the bad state can only be met through a fire sale of assets. A fire sale, however, leads to further depreciation of the value of a bank's remaining assets. This problem can be potentially addressed by the adoption of countercyclical capital buffers.

We identify three key factors a central bank should consider in deciding whether to confine its intervention activity to the interbank market only, or to step in early and assist the risky bank. These factors are: the volume of activity in the interbank market, the unconditional probability that the economy will find itself in an adverse state, and an accurate assessment of the level of insecurity of the risky bank.

Our baseline results suggest that assisting the risky bank is the preferable strategy for the central bank. The optimal level of capital reserves in that scenario may be so high, however, that it is possible this would impair the banks' ability to perform their core function of liquidity creation and credit provision. This finding reflects Diamond and Dybvig's (1986) argument that financial stability policy motivated solely by macroeconomic concerns may undermine the primary reason for the existence of banks. We find that an introduction of penalty rates charged by the central bank on liquidity assistance gives some way to alleviating this problem.

Finally, our paper emphasises the importance of a central bank's commitment to averting system-wide financial contagion through the interbank market. The widespread use of interest rate derivatives by non-financial firms has created a new channel linking the stability of the financial system to that of the entire economy. As of the end of 2014 , interest rate contracts account for more than $80 \%$ of OTC derivatives traded globally, with a notional amount outstanding of more than $\$ 500,000$ billion (Bank for International Settlements, 2015).

Furthermore, a well-functioning interbank market is crucial for efficient transmission of monetary policy or of emergency liquidity injections. Severe stress in that market will impair a central bank's ability to achieve its policy objectives. Our simulations suggest that an additional cost created by stress in the interbank market equivalent to just $4.5 \%$ of the initial value of banking system assets is sufficient for the policy of no assistance to become the least preferable strategy for the central bank, reflecting the spirit of the discussion above. 


\section{Conclusions}

Following the financial crisis of 2007 - 2009 defining the objectives of a central bank's financial stability policy has become less clear-cut, and continues to be a subject of an ongoing academic and policy debate.

An increasingly complex and interconnected economic system places a central bank at an intersection of monetary and fiscal policies, as a lender of last resort, a supervisor, and regulator of the banking sector, with additional responsibilities for monitoring the interbank money market (Freixas and Parigi, 2014).

Our model identifies the volume of interbank lending, the relative riskiness of the banks in the financial system, and the probability of the crisis becoming systemic as the key factors relevant for a central bank's financial stability policy design. Furthermore, the model highlights the importance of upholding the stability of the interbank money market for the security of the entire economic system.

Finally, our results establish the existence of a substitution effect between the scope of a central bank's assistance to an institution in distress, and the level of capital requirements. We find that active management of banks' assistance expectations yields similar results to changing capital requirements. An ill-designed financial stability policy that does not strike the right balance between the two, however, may result in significant economic costs. 


\section{Bibliography}

1. Acemoglu, D., Ozdaglar, A., Tahbaz-Salehi, A. (2015), "Systemic Risk and Stability in Financial Networks", American Economic Review, Vol. 105, pp. 564 - 608;

2. Acharya, V. V. (2009), "A theory of systemic risk and design of prudential bank regulation", Journal of Financial Stability, Vol. 5, pp. 224 - 255;

3. Aglietta, M., Mojon, B. (2014), "Central Banking", in: Berger, A. N., Molyneux, P., Wilson, J. O. S., eds., The Oxford Handbook of Banking, $2^{\text {nd }}$ edition, Oxford: Oxford University Press, pp. 432 - 452;

4. Allen, F., Gale, D. (2000), "Financial Contagion", Journal of Political Economy, Vol. 108, pp. 1 - 33;

5. Angelini, P., Neri, S., Panetta, F. (2014), "The Interaction between Capital Requirements and Monetary Policy", Journal of Money, Credit and Banking, Vol. 46, pp. 1073 - 1112;

6. Arnold, B., Borio, C., Ellis, L., Moshirian, F. (2012), "Systemic Risk, Macroprudential Policy Frameworks, Monitoring Financial Systems and the Evolution of Capital Adequacy", Journal of Banking \& Finance, Vol. 36, pp. $3125-3132 ;$

7. Bank for International Settlements (2015), OTC derivatives statistics at endDecember 2014, available online at: http://www.bis.org/publ/otc_hy1504.pdf;

8. Bagehot, W. (1873), Lombard Street: A Description of the Money Market, $3^{\text {rd }}$ edition, London: Henry S. King \& Co.;

9. Blinder, A. S., Ehrmann, M., Fratzscher, M., De Haan, J., Jansen, D.-J. (2008), Central Bank Communication and Monetary Policy: A Survey of Theory and Evidence, NBER Working Paper No. 13932, available online at: http://www.nber.org/papers/w13932.pdf;

10. Borio, C. (2003), Towards a macroprudential framework for financial supervision and regulation?, BIS Working Paper No. 128;

11. Brunnermeier, M. K. (2009), "Deciphering the Liquidity and Credit Crunch 2007 - 2008", Journal of Economic Perspectives, Vol. 23, pp. 77 - 100;

12. Brunnermeier, M. K., Pedersen, L. H. (2009), "Market Liquidity and Funding Liquidity", The Review of Financial Studies, Vol. 22, pp. 2201 - 2238;

13. Buiter, W. (2008), Can Central Banks Go Broke?, Centre for Economic Policy Research Insight No. 24;

14. Claessens, S. (2014), An Overview of Macroprudential Policy Tools, IMF Working Paper WP/14/214;

15. Dam, L., Koetter, M. (2012), “Bank Bailouts and Moral Hazard: Evidence from Germany", The Review of Financial Studies, Vol. 25, pp. 2343 - 2380;

16. Damodaran, A. (2015), Annual Returns on Stock, T.Bonds and T.Bills: 1928 Current, available online at: pages.stern.nyu.edu/ adamodar/New_Home_Page/datafile/histretSP.html; 
17. Dewatripont, M., Tirole, J. (1994), The Prudential Regulation of Banks, London: The MIT Press;

18. Diamond, D. W., Dybvig, P. H. (1983), "Bank Runs, Deposit Insurance, and Liquidity", Journal of Political Economy, Vol. 91, pp. 401 - 419;

19. Diamond, D. W., Dybvig, P. H. (1986), "Banking Theory, Deposit Insurance, and Bank Regulation", The Journal of Business, Vol. 59, pp. 55 - 68;

20. Domanski, D., Moessner, R., Nelson, W. (2014), "Central banks as lender of last resort: experiences during the 2007 - 2010 crisis and lessons for the future", Re-thiniking the lender of last resort, BIS Papers, No. 79, pp. 43 - 76;

21. Freixas, X., Parigi, B. M. (2014), "Lender of Last Resort and Bank Closure Policy - A Post-Crisis Perspective", in: Berger, A. N., Molyneux, P., Wilson, J. O. S., eds., The Oxford Handbook of Banking, $2^{\text {nd }}$ edition, Oxford: Oxford University Press, pp. 474 - 504;

22. Freixas, X., Parigi, B. M., Rochet, J.-C. (2000), "Systemic Risk, Interbank Relations and Liquidity Provision by the Central Bank", Journal of Money, Credit and Banking, Vol. 32, pp. 611 - 638;

23. Friedman, M. (1962), "Should There Be an Independent Monetary Authority?", in: Yeager, L. B., ed., In Search of a Monetary Constitution, Cambridge, MA: Harvard University Press, pp. 219 - 243;

24. Galati, G., Moessner, R. (2010), Macroprudential policy - a literature review, DNB Working Paper No. 267;

25. Giese, J., Nelson, B., Tanaka, M., Tarashev, N. (2013), How Could Macroprudential Policy Affect Financial System Resilience and Credit? Lessons from the Literature, Bank of England Financial Stability Paper No. 21;

26. Goodhart, C. A. E., Huang, H. (2005), "The lender of last resort", Journal of Banking \& Finance, Vol. 29, 1059 - 1082;

27. Goodhart, C. A. E., Schoenmaker, D. (1995), "Should the Functions of Monetary Policy and Banking Supervision Be Separated?", Oxford Economic Papers, Vol. 47, pp. 539 - 560;

28. Gorton, G., Huang, L. (2004), "Liquidity, Efficiency, and Bank Bailouts", American Economic Review, Vol. 94, pp. 455 - 483;

29. Hamilton, D. T., Cantor, R. (2006), "Measuring Corporate Default Rates", Moody's Special Comment, November 2006;

30. International Monetary Fund (2008), "Stress in Bank Funding Markets and Implications for Monetary Policy", World Economic and Financial Surveys: Global Financial Stability Report, pp. $73-108$;

31. Kahn, C. M., Santos, J. A. C. (2005), "Allocating bank regulatory powers: Lender of last resort, deposit insurance and supervision", European Economic Review, Vol. 49, pp. 2107 - 2136;

32. Kiyotaki, N., Moore, J. (2002), "Balance-Sheet Contagion", American Economic Review, Vol. 92, pp. 46 - 50;

33. Koulischer, F., Stuyven, D. (2014), "Central Bank Liquidity Provision and Collateral Quality", Journal of Banking \& Finance, Vol. 49, pp. 113 - 130; 
34. Mészáros, G. (2013), "Macroprudential Regulation: A Contradiction in Its Own Terms", Journal of Banking Regulation, Vol. 14, pp. 164 - 182;

35. Nagel, J. (2013), "The Consequences of an Ineffective Money Market", Revue d'économie financière, Vol. 111, pp. 199 - 213;

36. Nijskens, R. (2014), "A Sheep in Wolf's Clothing: Can a Central Bank Appear Tougher Than It Is?", Journal of Banking \& Finance, Vol. 48, pp. 94 - 103;

37. Ratnovski, L. (2009), "Bank liquidity regulation and the lender of last resort", Journal of Financial Intermediation, Vol. 18, pp. 541 - 558;

38. Repullo, R., Suarez, J. (2013), "The Procyclical Effects of Bank Capital Regulation", The Review of Financial Studies, Vol. 26, pp. 452 - 490;

39. Rochet, J. C., Tirole, J. (1996), "Interbank Lending and Systemic Risk", Journal of Money, Credit, and Banking, Vol. 28, pp. 733 - 762;

40. Slovik, P., Cournède, B. (2011), Macroeconomic Impact of Basel III, OECD Economics Department Working Paper No. 844;

41. Thornton, H. (1802), An Enquiry into the Nature and Effects of the Paper Credit of Great Britain, London: Hatchard;

42. Van den Heuvel, S. J. (2008), "The welfare cost of bank capital requirements", Journal of Monetary Economics, Vol. 55, pp. 298 - 320;

43. VanHoose, D. (2007), "Theories of bank behaviour under capital regulation", Journal of Banking \& Finance, Vol. 31, pp. 3680 - 3697;

44. Vinogradov, D. (2012), "Destructive effects of constructive ambiguity in risky times", Journal of International Money and Finance, Vol. 31, pp. 1459 - 1481;

45. Wagner, W. (2007), "The liquidity of bank assets and banking stability", Journal of Banking \& Finance, Vol. 31, pp. 121 - 139. 


\section{Appendix A: Derivation of the Interbank Loan Size Functions}

\section{The Risky Bank}

a) No Central Bank Assistance

If the central bank provides no assistance to the risky bank at $t=1$ it earns its expected returns with probability $p\left(S_{H}\right)$, and 0 otherwise. As a result, its expected terminal value is given by

$$
E\left[V_{u, T}\right]=p\left(S_{H}\right) \times\left[R_{H}\left(a_{t}+\frac{1}{1+\kappa} i_{t}\right)-\rho i_{t}+k_{u, t}\right]
$$

b) Central Bank Assistance:

Should the central bank decide to assist the risky bank at $t=1$ and provide sufficient funding to restore the bank's balance sheet to its initial position, the bank's terminal value is equal to $a_{t}+\kappa a_{t}$. Consequently, its expected terminal value of the risky bank is given by

$$
\begin{aligned}
E\left[V_{u, T}\right] & =p\left(S_{H}\right) \times\left[R_{H}\left(a_{t}+\frac{1}{1+\kappa} i_{t}\right)-\rho i_{t}+k_{u, t}\right] \\
+ & {\left[1-p\left(S_{H}\right)\right]\left(a_{t}+\kappa a_{t}\right) }
\end{aligned}
$$

As the additional term in equation (A.2) is independent of $i_{t}$, both (A.1) and (A.2) provide the same value for the size of the interbank loan which maximises the expected terminal values of the risky bank.

Therefore:

$$
E\left[V_{u, T}\right]=p\left(S_{H}\right) \times\left[R_{H}\left(a_{t}+\frac{1}{1+\kappa} i_{t}\right)-\rho i_{t}+k_{u, t}\right]
$$

Since $\rho=1+\rho_{0} \frac{i_{t}}{a_{t}^{\prime}}$

$$
\begin{aligned}
E\left[V_{u, T}\right] & =p\left(S_{H}\right) \times\left[R_{H}\left(a_{t}+\frac{1}{1+\kappa} i_{t}\right)-\left(1+\rho_{0} \frac{i_{t}}{a_{t}}\right) i_{t}\right. \\
& \left.+\kappa\left(a_{t}+\frac{1}{1+\kappa} i_{t}\right)\right]
\end{aligned}
$$

Taking the first derivative with respect to $i_{t}$ :

$$
\frac{\partial E\left[V_{u, T}\right]}{\partial i_{t}}=p\left(S_{H}\right) \times\left[R_{H} \frac{1}{1+\kappa}-2 \rho_{0} \frac{i_{t}}{a_{t}}+\frac{\kappa}{1+\kappa}\right]
$$

Setting the first derivative equal to zero:

$$
\begin{gathered}
0=p\left(S_{H}\right) \times\left[R_{H} \frac{1}{1+\kappa}-2 \rho_{0} \frac{i_{t}}{a_{t}}+\frac{\kappa}{1+\kappa}\right] \\
i_{t}=\frac{\left(R_{H}+\kappa\right) a_{t}}{2 \rho_{0}(1+\kappa)}
\end{gathered}
$$

Since $a_{t}=\frac{1}{1+\kappa^{\prime}}$

$$
i_{t}=\frac{R_{H}+\kappa}{2 \rho_{0}(1+\kappa)^{2}}
$$


This indicates the size of the interbank loan that maximises the expected terminal value of the risky bank regardless of which strategy the central bank selects. 


\section{The Prudent Bank}

a) No Central Bank Assistance:

If the central bank decides not to intervene at $t=1$ the effects on the prudent bank's terminal value depend on whether the inequality $\frac{R_{L}-1}{R_{L}} a_{t}<i_{t}$ holds. Two cases are relevant.

For $\frac{R_{L}-1}{R_{L}} a_{t} \geq i_{t}$, the net earnings of the prudent bank exceed the value of the interbank loan to be written off, resulting in the following expected terminal value:

$$
\begin{aligned}
& E\left[V_{s, T}\right]=p\left(S_{H}\right) \times\left[R_{L}\left(a_{t}-i_{t}\right)+\rho i_{t}+k_{s, t}\right] \\
& \quad+\left[1-p\left(S_{H}\right)\right] p\left(S_{L}\right)\left[R_{L}\left(a_{t}-i_{t}\right)-i_{t}+k_{s, t}\right] \\
& \quad+\left[1-p\left(S_{H}\right)\right]\left[1-p\left(S_{L}\right)\right]\left[a_{t}+\kappa a_{t}\right]
\end{aligned}
$$

As last term in equation (A.10) is independent of $i_{t}$, the size of the interbank loan which maximises the expected terminal value of the risky bank can be computed as:

$$
\begin{aligned}
& E\left[V_{s, T}\right]=p\left(S_{H}\right) \times\left[R_{L}\left(a_{t}-i_{t}\right)+\rho i_{t}+k_{s, t}\right] \\
& \quad+\left[1-p\left(S_{H}\right)\right] p\left(S_{L}\right)\left[R_{L}\left(a_{t}-i_{t}\right)-i_{t}+k_{s, t}\right]
\end{aligned}
$$

which is equivalent to:

$$
\begin{aligned}
E\left[V_{S, T}\right] & =p\left(S_{H}\right) \times\left[R_{L} a_{t}-R_{L} i_{t}+i_{t}+\rho_{0} \frac{i_{t}^{2}}{a_{t}}+\kappa a_{t}\right. \\
& \left.-p\left(S_{L}\right)\left[R_{L} a_{t}-R_{L} i_{t}-i_{t}+\kappa a_{t}\right]\right] \\
& +p\left(S_{L}\right)\left[R_{L} a_{t}-R_{L} i_{t}-i_{t}+\kappa a_{t}\right]
\end{aligned}
$$

It follows, by taking the first derivative with respect to $i_{t}$ and setting it equal to zero:

$$
\begin{gathered}
\frac{\partial E\left[V_{s, T}\right]}{\partial i_{t}}=R_{L}\left[p\left(S_{H}\right) p\left(S_{L}\right)-p\left(S_{H}\right)-p\left(S_{L}\right)\right] \\
+\left[p\left(S_{H}\right) p\left(S_{L}\right)+p\left(S_{H}\right)-p\left(S_{L}\right)\right]+2 p\left(S_{H}\right) \rho_{0} \frac{i_{t}}{a_{t}} \\
0=R_{L}\left[p\left(S_{H}\right) p\left(S_{L}\right)-p\left(S_{H}\right)-p\left(S_{L}\right)\right]+\left[p\left(S_{H}\right) p\left(S_{L}\right)+p\left(S_{H}\right)-p\left(S_{L}\right)\right] \\
+2 p\left(S_{H}\right) \rho_{0} \frac{i_{t}}{a_{t}} \\
i_{t}=\frac{\left[R_{L}\left[p\left(S_{H}\right)+p\left(S_{L}\right)-p\left(S_{H}\right) p\left(S_{L}\right)\right]+\left[p\left(S_{L}\right)-p\left(S_{H}\right)-p\left(S_{H}\right) p\left(S_{L}\right)\right]\right] a_{t}}{2 p\left(S_{H}\right) \rho_{0}}
\end{gathered}
$$

Since $a_{t}=\frac{1}{1+\kappa^{\prime}}$

$$
i_{t}=\frac{R_{L}\left[p\left(S_{H}\right)+p\left(S_{L}\right)-p\left(S_{H}\right) p\left(S_{L}\right)\right]+\left[p\left(S_{L}\right)-p\left(S_{H}\right)-p\left(S_{H}\right) p\left(S_{L}\right)\right]}{2 p\left(S_{H}\right) \rho_{0}(1+\kappa)}
$$

Equation (A.16) denotes the size of the interbank loan that maximises the expected terminal value of the prudent bank if the central bank decides not to intervene at $t=1$, and the prudent bank's net earnings are sufficient to enable it to write off the interbank loan. 
For $\frac{R_{L}-1}{R_{L}} a_{t}<i_{t}$, the prudent bank's net earnings are not sufficient to absorb the loss associated with writing off the interbank loan. It therefore requires the central bank's assistance in both the neutral and the bad state of the economy. Consequently, its terminal value function is given by the following expression:

$$
E\left[V_{s, T}\right]=p\left(S_{H}\right) \times\left[R_{L}\left(a_{t}-i_{t}\right)+\rho i_{t}+k_{s, t}\right]+\left[1-p\left(S_{H}\right)\right]\left(a_{t}+\kappa a_{t}\right)
$$

Taking the first derivative with respect to $i_{t}$ and setting it equal to zero:

$$
\begin{gathered}
\frac{\partial E\left[V_{s, T}\right]}{\partial i_{t}}=p\left(S_{H}\right)\left[-R_{L}+1+2 \rho_{0} \frac{i_{t}}{a_{t}}\right] \\
0=p\left(S_{H}\right)\left[-R_{L}+1+2 \rho_{0} \frac{i_{t}}{a_{t}}\right] \\
i_{t}=\frac{\left(R_{L}-1\right) a_{t}}{2 \rho_{0}}
\end{gathered}
$$

Since $a_{t}=\frac{1}{1+\kappa^{\prime}}$

$$
i_{t}=\frac{R_{L}-1}{2 \rho_{0}(1+\kappa)}
$$

Equation (A.21) gives the size of the interbank loan that maximises the expected terminal value of the prudent bank if the central bank decides not to intervene at $t=1$, and the prudent bank's net earnings are insufficient to enable it to write off the interbank loan.

b) Central Bank Intervenes in the Interbank Market:

If the central bank decides to intervene in the interbank market it provides the prudent bank with the principal amount of the interbank loan in the neutral state, and assists it in the bad state, resulting in the following expected terminal value function:

$$
\begin{aligned}
& E\left[V_{s, T}\right]=p\left(S_{H}\right) \times\left[R_{L}\left(a_{t}-i_{t}\right)+\rho i_{t}+k_{s, t}\right] \\
& \quad+\left[1-p\left(S_{H}\right)\right] p\left(S_{L}\right)\left[R_{L}\left(a_{t}-i_{t}\right)+i_{t}+k_{s, t}\right] \\
& \quad+\left[1-p\left(S_{H}\right)\right]\left[1-p\left(S_{L}\right)\right]\left(a_{t}+\kappa a_{t}\right)
\end{aligned}
$$

Taking the first derivative with respect to $i_{t}$ and setting it equal to zero:

$$
\begin{gathered}
\frac{\partial E\left[V_{s, T}\right]}{\partial i_{t}}=\left[p\left(S_{H}\right)+p\left(S_{L}\right)-p\left(S_{H}\right) p\left(S_{L}\right)\right]\left(-R_{L}+1\right)+2 p\left(S_{H}\right) \rho_{0} \frac{i_{t}}{a_{t}} \\
0=\left[p\left(S_{H}\right)+p\left(S_{L}\right)-p\left(S_{H}\right) p\left(S_{L}\right)\right]\left(-R_{L}+1\right)+2 p\left(S_{H}\right) \rho_{0} \frac{i_{t}}{a_{t}} \\
i_{t}=\frac{\left[p\left(S_{H}\right)+p\left(S_{L}\right)-p\left(S_{H}\right) p\left(S_{L}\right)\right]\left(R_{L}-1\right) a_{t}}{2 p\left(S_{H}\right) \rho_{0}}
\end{gathered}
$$

Since $a_{t}=\frac{1}{1+\kappa^{\prime}}$

$$
i_{t}=\frac{\left(R_{L}-1\right)\left[p\left(S_{H}\right)+p\left(S_{L}\right)-p\left(S_{H}\right) p\left(S_{L}\right)\right]}{2 p\left(S_{H}\right) \rho_{0}(1+\kappa)}
$$

Equation (A.26) depicts the size of the interbank loan that maximises the expected terminal value of the prudent bank if the central bank decides to intervene in the interbank market at $t=1$. 
c) Central Bank Assists Risky Bank at $t=1$ :

Finally, if the central bank assists the risky bank at $t=1$, the prudent bank will to receive the principal amount of the interbank loan in the neutral state, and will be resolved in the bad state, as the central bank only assists one commercial bank. Consequently, its expected terminal value is given by the following function:

$$
\begin{aligned}
& E\left[V_{s, T}\right]=p\left(S_{H}\right) \times\left[R_{L}\left(a_{t}-i_{t}\right)+\rho i_{t}+k_{s, t}\right] \\
& \quad+\left[1-p\left(S_{H}\right)\right] p\left(S_{L}\right)\left[R_{L}\left(a_{t}-i_{t}\right)+i_{t}+k_{s, t}\right]
\end{aligned}
$$

This function's first derivative with respect to $i_{t}$ is equivalent to (A.23). As a result, the optimal size of the loan if the central bank assists the risky bank at $t=1$ is given by equation (A.26). 
IFC workshop on "Combining micro and macro statistical data for financial stability analysis. Experiences, opportunities and challenges" Warsaw, Poland, 14-15 December 2015

\title{
Systemic risk, interbank market contagion, and the lender of last resort function ${ }^{1}$
}

\author{
Marcin Jerzy Michalski, Michael Bowe, Olga Kolokolova, \\ University of Manchester/Manchester Business School
}

1 This presentation was prepared for the meeting. The views expressed are those of the authors and do not necessarily reflect the views of the BIS or the central banks and other institutions represented at the meeting. 


\section{Systemic Risk, Interbank Market Contagion, and the Lender of Last Resort Function}

Michael Bowe, Olga Kolokolova, Marcin Jerzy Michalski

Alliance Manchester Business School

The University of Manchester

Irving Fisher Committee Workshop

Warsaw, 14 ${ }^{\text {th }}$ December 2015 


\section{Introduction and Motivation}

- The Global Financial Crisis of 2007 - 2009 highlighted the shortcomings of financial stability policy based solely upon traditional lending of last resort and microprudential bank regulation.

- Insufficiency of lending of last resort restricted solely to lending to solvent but illiquid financial institutions:

(1) Illiquidity and insolvency become almost indistinguishable in crisis conditions;

(2) Failure of constructive ambiguity: sudden changes in a priori assistance expectations;

- Regulatory paradigm shift from micro- towards macroprudential bank regulation.

- Role of a central bank in an increasingly complex and interconnected economic system:

- Placed at an intersection of monetary and fiscal policies;

(2) Lender of Last Resort (LOLR);

(3) Supervisor and regulator of the banking sector;

(1) Responsibility for monitoring the condition of the interbank market.

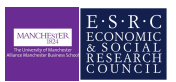




\section{Introduction and Motivation}

Contribution of the Model

- We examine the determinants of financial stability policy design within a theoretical model of a macrofinancial system consisting of:

(- A central bank (CB) acting as both the lender of last resort and the regulator of the financial system;

(2) Two commercial banks interacting through an interbank (IB) market;

(3) Non-financial sector operating in the real economy.

- Novel features of the model:

(1) Highlights central role of the IB market as channel for spillovers or contagion;

(2) Pre-announcement of $\mathrm{CB}$ intervention strategy to provide forward guidance and manage expectations;

(3) Analyses interaction of policy trade-off between ex ante measures (capital requirements) and ex post assistance in formulating CB policy. 


\section{Related Literature}

\section{Related Literature I}

- The literatures analysing the lender of last resort function, financial contagion, and prudential bank regulation evolved largely independently until recently.

- Lender of last resort literature:

(1) Original objectives of lending to solvent but illiquid institutions formulated by Thornton (1802) and Bagehot (1873).

(2) The efficient functioning of a banking system requires either a formal deposit insurance scheme or a commitment to LOLR (Diamond and Dybvig, 1983).

(3) LOLR policies involve a trade-off between preventing financial contagion and creating moral hazard (Goodhart and Huang, 2005). This can be addressed by the use of constructive ambiguity.

(4) The traditional approach to LOLR may lead to a simplistic analysis of financial stability, and an artificial separation of LOLR and bail-out interventions (Freixas and Parigi, 2014). 


\section{Related Literature}

\section{Related Literature II}

- Financial contagion literature:

(1) The IB market is the most prominent channel of financial contagion.

(2) It interconnects banks' balance sheets and rapidly propagates one agent's distress throughout the system (Allen and Gale, 2000, Freixas, et al., 2000).

(3) The IB market is a conduit for adverse feedback from the financial system into the real economy (IMF, 2008, Brunnermeier, 2009).

(4) The growing importance of this market calls for new $\mathrm{CB}$ operating frameworks providing grater flexibility when its liquidity is compromised (Domanski, et al., 2014).

- Prudential bank regulation literature:

(- Microprudential bank regulation: limiting financial distress of individual institutions by ensuring they are well-capitalised and managed prudently (Dewatripont and Tirole, 1994, Borio, 2003, VanHoose, 2007).

(2) Macroprudential bank regulation: limiting the risk of system-wide financial distress resulting in substantial loss of real output (Borio, 2003, Galati and Moesnner, 2010, Claessens, 2014).

(3) Recent studies undertake primarily qualitative assessment (Arnold, et al., 2012, Giese, et al., 2013, Mészáros, 2013), or provide early estimates of its economic impact (Slovik and Cournède, 2011, Angelini, et al., 2014). 


\section{The Model}

Commercial Banks I

- Two commercial banks of the same initial size, but with different exogenously-determined risk profiles.

\begin{tabular}{l|l}
\multicolumn{2}{c}{ Initial balance sheet structure } \\
\hline Assets & Liabilities \\
Risky Assets $\left(a_{t}\right)$ & Long-term Liabilities $(I)$ \\
Reserves $\left(k_{t}\right)$ & Equity Capital $(c)$
\end{tabular}

- The banks interact through the IB market to reallocate their initial endowment of risky assets. This is done by issuing an IB loan, $i_{t}$.

- The lending bank diversifies its portfolio of assets (prudent bank). The borrowing bank uses the additional funds to leverage its investment position (risky bank).

- The IB loan pays a gross interest rate $\rho$, such that $\rho=1+\rho_{0} \times \frac{i_{t}}{a_{t}}$.

- The level of capital reserves corresponds to a certain proportion of the value of risky assets the two banks hold, stipulated as a total regulatory capital ratio, $\kappa$. 


\section{The Model}

\section{Commercial Banks II}

- The investment payoffs to the banks differ and realise consecutively.

- The payoff to the risky bank at $t=1$ is given by:

$$
\widetilde{R_{H}}=\left\{\begin{array}{l}
R_{H} \text { with probability } p\left(S_{H}\right) \\
0 \text { with probability } 1-p\left(S_{H}\right)
\end{array}\right.
$$

- The payoff to the prudent bank at $t=2$ is given by:

$$
\widetilde{R_{L}}=\left\{\begin{array}{l}
R_{L} \text { with probability } p\left(R_{L} \mid R_{H}\right)=1 \\
R_{L} \text { with probability } p\left(R_{L} \mid 0\right)=p\left(S_{L}\right) \\
0 \text { with probability } 1-p\left(S_{L}\right)
\end{array}\right.
$$

- $p\left(S_{H}\right.$ is modelled explicitly as a logistic function:

$$
p\left(S_{H}\right)=\frac{1}{1+e^{\alpha+\beta\left(a_{t}\right)}}=\frac{1}{1+e^{\alpha+\beta\left(\frac{1}{1+\kappa}\right)}}
$$

- The terminal values of the two banks can be expressed as:

$$
\begin{aligned}
& V_{u, T}=\max \left(\left[R_{H}\left(a_{t}+i_{t}\right)-\rho i_{t}+k_{u, t}\right], 0\right) \\
& V_{s, T}=\max \left(\left[R_{L}\left(a_{t}-i_{t}\right)+\rho i_{t}+k_{s, t}\right], 0\right)
\end{aligned}
$$




\section{The Model}

- Primary role of the non-financial firms is to generate real economic output outside the financial system, undertaken by appropriately investing the funds obtained from banks in positive NPV projects, generating an average rate of return, $r$.

- The CB's objective is to maximise the difference between the volume of economic output generated in the system and the expected costs of economic distress.

$$
V_{C B}=E[\Omega]-\Phi-E[s]-E[\Gamma]-E[\Lambda]+E[\Psi]
$$

(1) $\Omega$ : the volume of economic output;

(2) $\Phi$ : the opportunity cost of holding capital reserves;

(3) $s$ : the cost of stress in the IB market;

(4) $\Gamma$ : the loss of output due to bank failure;

(6) $\Lambda$ : the cost of assisting a bank in distress;

6 : the expected value of liquidity assistance repayment.

- To achieve its policy objective, the CB chooses one of the following three strategies:

(1) Allow a bank in distress to be resolved;

(2) Intervene in the IB market and guarantee the repayment of any IB loans, while still allowing a bank in distress to be resolved;

(3) Attempt to avert a crisis altogether by fully assisting a bank in distress. 


\section{The Model}

\section{Structure and Evolution of the Game}

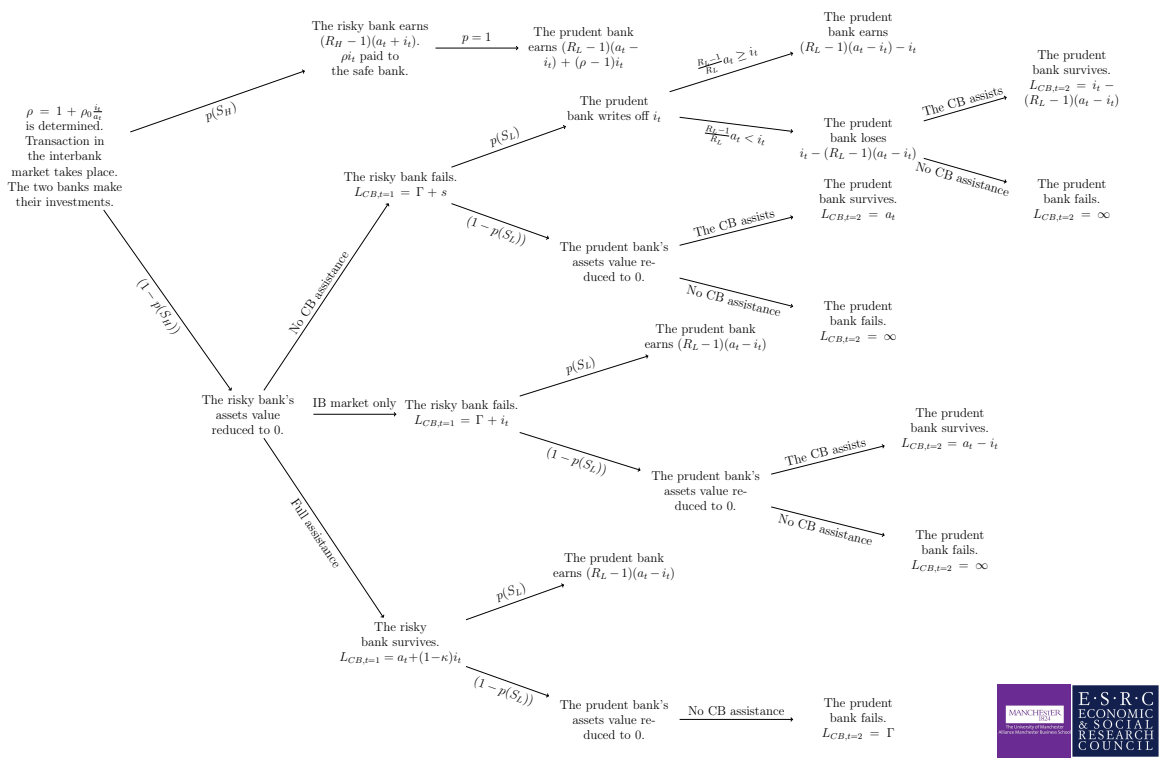




\section{Simulation Experiments and Policy Implications}

\section{Baseline Simulation}

- Given the CB's crisis response strategy, chosen and publicised at $t=0$, we derive the size of the interbank loan that maximises the the terminal values of the two commercial banks.

- We then simulate the interactions in the model for plausible values of the specified parameters in order to examine the optimal central bank policy.

\begin{tabular}{l|l} 
Parameter & Assumed value \\
\hline$R_{H}$ & 1.2 \\
$R_{L}$ & 1.05 \\
$r$ & 0.1 \\
$\rho_{0}$ & 0.5 \\
$\alpha$ & -1 \\
$\beta$ & 0.5 \\
$p\left(S_{L}\right)$ & 0.7 \\
$\delta_{s}$ & 0.75 \\
$\delta_{u}$ & 0.2 \\
$s$ & 0.1 \\
$r_{p}$ & 0 \\
\hline
\end{tabular}




\section{Simulation Experiments and Policy Implications}

\section{Baseline Simulation}

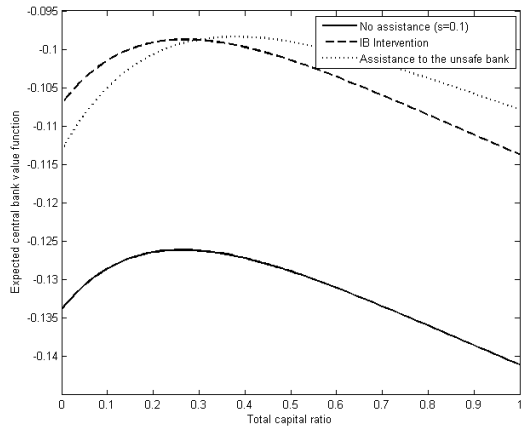

- This result indicates there exists an optimal level of capital requirements which maximises the CB's value function.

- The marginal benefits from increasing capital requirements towards the optimal level are diminishing.

- The no intervention strategy generates the worst outcome, unless we invoke an extreme assumption that a crisis does not entail any costs of stress in the IB market. 


\section{Simulation Experiments and Policy Implications}

Stability of the Interbank Market
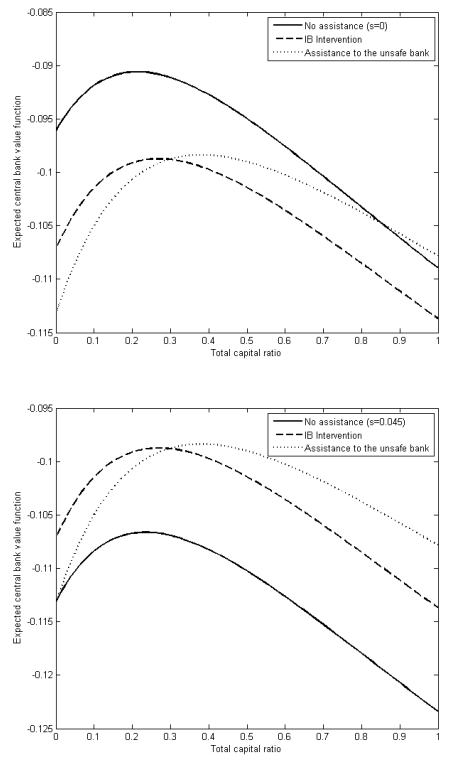

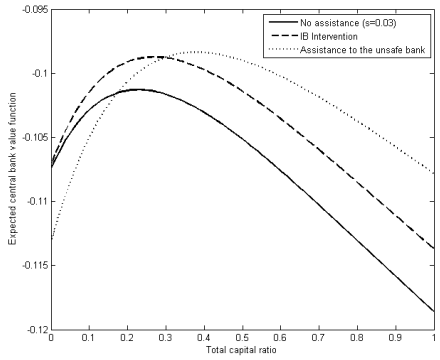

- The CB policy will change if there is a mechanism ensuring that the functioning of the IB market is not compromised during a crisis.

- The Liquidity Coverage Ratio could be a potential solution to this problem. 


\section{Simulation Experiments and Policy Implications}

Trade-Off Between Expected Scope of Intervention and the Level of Capital Requirements

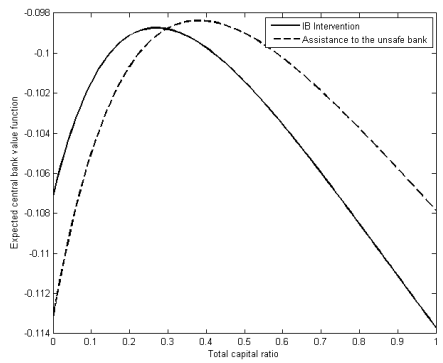

- A bank's risk appetite is affected both by its assistance expectations, and by the capital requirements it has to comply with.

- The absence of an implicit guarantee of CB assistance enhances market discipline, while high capital requirements make riskier investment more costly.

- Substitution effect: the optimal level of capital requirements increases with the extent of CB's commitment to intervene. 


\section{Simulation Experiments and Policy Implications}

Volume of IB Lending and the CB's Assessment of the Riskiness of the Assisted Bank

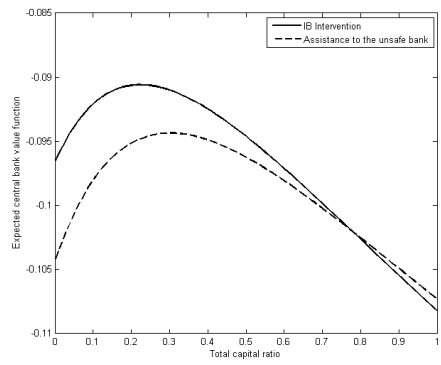

- If the CB's intervention is restricted to guaranteeing the repayment of the IB loan, the value of that guarantee will become its pure loss.

- The lower the volume of IB lending, the lower the CB's loss.

- The CB's strategy preferences therefore depend on the volume of IB activity.

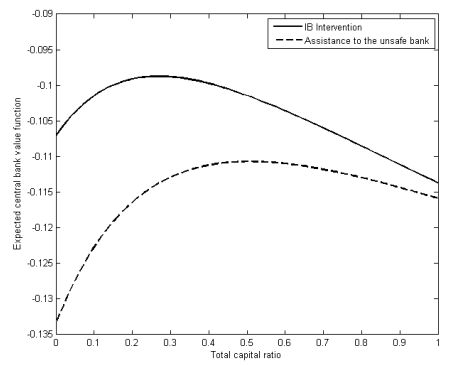

- The discount factor applied to the repayment of liquidity injections reflects the CB's assessment of both the probability that the assisted bank is going to repay the funds, and the length of time required to do so. 


\section{Conclusions}

- To achieve the objectives of macroprudential financial stability policy CBs have to be proactive and fully utilise their information about the condition of the financial system in order to accurately gauge the adverse affects of financial stress on the real economy.

- Key factors influencing optimal financial stability policy design:

(1) Scale of interbank market activity;

(2) Relative risky attitudes of commercial banks in the system;

(3) Probability of systemic distress.

- There is a substitution effect between the scope of a CB's assistance to an institution in distress and the level of regulatory capital requirements.

- An ill-designed policy that does not strike the right balance between the two may impose significant economic costs. 
Thank you for your attention. 